\title{
Synonymie und ihre Bedeutung in der einsprachigen Lexikographie
}

\section{Vorbemerkung}

In diesem Beitrag geht es um die Rolle der Synonymierelation bei der semantischen Erklärung der Lemmata im einsprachigen Wörterbuch durch die Lexikographen und beim Verstehen der lexikalischen Paraphrasen innerhalb von Wörterbucheinträgen durch den Wörterbuchbenutzer. ${ }^{1}$

\subsection{Erklärung von Wortbedeutungen als historisch konstanter Zweck der einsprachigen Lexikographie}

Die Geschichte der Lexikographie zeigt, daß einsprachige Wörterbücher in recht unterschiedlichen wissenschaftsinternen und gesellschaftlichen Begründungszusammenhängen standen und stehen. ${ }^{2}$ Über die Zwecke von einsprachigen Wörterbüchern gibt es daher differierende Ansichten. Ein spezifischer Zweck jedoch wird von allen Lexikographen meines Wissens stets explizit betont: mit ihren Wörterbucheinträgen - insbesondere mit den lexikalischen Paraphrasen - wollen sie dem Wörterbuchbenutzer Wortbedeutungen erklären. ${ }^{3}$ Das mögen - stellvertretend für viele - einige Zitate belegen.

\section{J.C. Adelung führt aus:}

“ [...] ich legte mir gleich Anfangs die Pflicht auf, den Begriff eines jeden Wortes und einer jeden Bedeutung desselben auf das Genaueste zu bestimmen [...] $\cdots 4$

W. Betz schreibt :

"Das Hauptziel des Buches bleibt nach wie vor im Sinne von Hermann Paul die Bedeutungsgeschichte und damit zugleich ein sehr modernes Ziel: die diachronische und synchronische Semantik des Deutschen." 5

G. Wahrig führt aus:

"Insbesondere sollen die Bedeutung der Wörter und ihre Verwendungsmöglichkeit im lebendigen Sprachzusammenhang [...] für jeden verständlich dargestellt werden." 6

In einer Forschungssituation, in der sich Sprachwissenschaftler verstärkt semantischen Fragen zuwandten, lag es daher nahe, die semantisch interessanten Teile der lexikographischen Praxis näher zu studieren; interessant war für die Semantik vor allem die Praxis der semantisch-lexikalischen Paraphrasierung in den Wörterbucheinträgen. Man kann daher ein in den 
beiden letzten Jahrzehnten zunehmendes theoretisches Interesse an der lexikographischen Praxis und den Wörterbüchern konstatieren.

\subsection{Lexikographische Praxis und einsprachige Wörterbücher im Spiegel struktureller Sprachauffassung}

Der genannte Trend läßt sich ablesen an zahlreichen Arbeiten, die insbesondere zur angewandten Semantik in der Lexikographie erschienen sind. ${ }^{7}$ Ohne deren Ergebnisse wüßten wir sehr viel weniger über die Bedeutungsauffassung der Lexikographen, über ihre lexikalisch-semantischen Beschreibungsmethoden, über die sprachtheoretischen Bezüge lexikographischer Praxis und über die theorievermittelten, wissenschaftspraktischen Prinzipien, denen sie folgte und folgt.

Die (in Anm.7) aufgeführten Arbeiten haben gewisse Gemeinsamkeiten. Sie arbeiten entweder die sprachtheoretischen Voraussetzungen und Konsequenzen spezifischer lexikographischer Praxis in ihrem wissenschaftshistorischen Zusammenhang heraus, oder sie analysieren Wörterbücher im Spiegel strukturell orientierter sprachtheoretischer Konzepte. Nur in der Arbeit von $\mathrm{H}$. Henne wurden bisher meines Wissens beide Möglichkeiten - insbesondere hinsichtlich der Semantik - systematisch integriert. ${ }^{8}$ Allen genannten Arbeiten ist weiterhin mehr oder weniger gemeinsam, daß sie von irgendeiner Variante der strukturellen Sprachauffassung bzw. der strukturellen Semantik ausgehen. Sie betrachten daher die Sprache (langue) als ein System von Sprachzeichen und Regeln zu deren Kombination. Demgemäß analysieren sie Wörterbucheinträge nach strukturellen (nicht strukturalistischen!) Methoden. Das Interesse gilt dabei besonders der Binnenstruktur der lexikalischen Paraphrase ${ }^{9}$ und den - in den Wörterbüchern faßbaren - lexikalisch-semantischen Mikrostrukturen ${ }^{10}$, kurz: über das "Abbild des Wortschatzes"11, das einsprachige Wörterbuch, will (und hat) man auch etwas über die Struktur des Wortschatzes der je kodifizierten Sprache erfahren. Der bei der Analyse verwendete Zeichenbegriff sowie die Bedeutungsauffassung ist meistens wahrscheinlich weniger Saussure selbst als der Saussure-Rezeption oder einem jener Autoren verpflichtet, die sich - wie z.B. Hjemslev - selbst als Saussure-Nachfolger begreifen. ${ }^{12}$

Der sprachtheoretische Zugriff dieser Arbeiten, der hier freilich nur grob skizziert wurde, ist in den meisten Fällen durch die, von den Lexikographen selbst kundgetane Sprachauffassung legitimiert; das gilt sogar dann, wenn die analysierten Wörterbücher vor Saussure geschrieben wurden.

Wenn die Lexikographen mit ihren einsprachigen alphabetischen Wörterbüchern - wie im Abschnitt 1.1. angedeutet - stets u.a. auch den Zweck verfolgten und verfolgen, dem Benutzer ihrer Wörterbücher Wortbedeu- 
tungen zu erklären, dann liegt es offensichtlich nahe, einmal nicht zu fragen, wie man als Sprachwissenschaftler im Lichte struktureller Sprachtheorien die lexikographischen Wortbedeutungserklärungen theoriebezogen interpretieren und somit theoretisch einordnen und verstehen kann, um damit u.a. die lexikographisch-semantische Praxis einerseits und lexikalische Semantik andererseits mit der Absicht ihrer wechselseitigen Erhellung zu reflektieren, sondern auch einmal Wörterbucheinträge genauer zu analysieren innerhalb etwa des folgenden allgemeinen Fragerahmens: Wie kann die Sprachwissenschaft erklären, daß ein Wörterbuchbenutzer die gegebene nen lexikographsichen Wortbedeutungserklärungen, insbesondere die lexikalischen Paraphrasen, überhaupt verstehen kann, oder: In welchen kommunikativen Handlungssituationen kann der Wörterbuchbenutzer sie sinnvoll verwenden?

Obwohl es nützlich wäre, den an diesem Fragerahmen orientierten, nachfolgend allerdings nur umrißhaft vorgeschlagenen Ansatz in Auseinandersetzungen mit den (in Anm.7) genannten Arbeiten zu entwickeln, kann das hier aus Platzgründen nicht geschehen. Ich gehe daher lediglich von einigen allgemeinen und zugleich einfachen Vorüberlegungen aus.

\subsection{Das Formulieren von Wörterbucheinträgen als sprachliches Handeln}

Die Praxis derjenigen Lexikographen, die einsprachige alphabetische Wörterbücher verfassen, ist im Detail sehr verschieden. ${ }^{13}$ Abstrahiert man von diesen Details, dann wird eine Folge von wissenschaftspraktischen Handlungen erkennbar, die im Prinzip stets gleich, nämlich wie folgt, abläuft:

(1) Eine sog. empirische Materialbasis wird zusammengestellt, d.h. Texte oder Textausschnitte (Belege) werden gesammelt.

(2) Aus dem "Material" werden diejenigen Wörter herausgenommen, die als Lemmata angesetzt werden.

(3) Diese werden aber nicht etwa sprachlich isoliert, vielmehr werden zu diesen Wörtern neue Texte formuliert, die Wörterbucheinträge. ${ }^{14}$

Die Lexikographie hat es daher weniger mit isolierten Wörtern, sondern vor allem mit Texten und Textausschnitten zu tun.

Das schriftliche Formulieren der Wörterbucheinträge nun ist offensichtlich eine sprachliche Handlung, nämlich ein (auch metakommunikativer) Schreibakt, der einer stark ausgeprägten lexikographischen Tradition unterworfen ist. Der hier interessierende Teilzweck dieser lexikographischen Schreibakte besteht darin, dem Wörterbuchbenutzer die Bedeutung (oder: die Bedeutungen) des Lemmas zu erklären. Dazu muß der Lexikograph 
diejenigen kommunikativen Handlungssituationen antizipieren, in denen oder anschließend an die der Wörterbuchbenutzer, indem er Leseakte ausführt, im Wörterbuch nach Wortbedeutungen suchen wird. Nur durch solche Antizipationen kann der Lexikograph hoffen, die Erwartungen zu erfüllen, die vom Wörterbuchbenutzer an die kodifizierten Ergebnisse seiner Schreibakte, die Wörterbucheinträge, gestellt werden. ${ }^{15}$

Diese - hier nur grob angedeutete - Sichtweise der lexikographischen Praxis legt es m.E. nahe - im Unterschied zu den (in Anm.7) genannten Arbeiten - die Ansätze zur sog. Gebrauchstheorie der sprachlichen Bedeutung heranzuziehen. ${ }^{16}$ Das kann nachfolgend nicht im Einzelnen geschehen; es soll damit nur der allgemeine theoretische Rahmen genannt sein, in dem argumentiert wird.

\subsection{Zum Verhältnis von inhaltlichen Ähnlichkeitsbeziehungen zwischen sprachlichen Ausdrücken und theoretischen Synonymiebegriffen}

Im Folgenden gebe ich vorab einige Hinweise, wie ich - in dem soeben genannten Rahmen - das Verhältnis von inhaltlichen Ähnlichkeitsbeziehungen zwischen sprachlichen Ausdrücken einerseits, von denen im sprachlichen Handeln Gebrauch gemacht wird, und theoretischen Synonymiebegriffen andererseits verstanden wissen will. Dazu gehe ich von folgendem Beispiel aus:

BEISPIEL Nr. 1

Der zwölfjährige Matthias sagt zu seinem gleichaltrigen Freund Bobby: "Schade, daß du zu meinem Geburtstag nicht da warst; ich bab nämlich einen tollen Kajak bekommen." Bobby fragt daraufhin: "Was ist denn ein Kajak? " Matthias gibt ihm folgende Erläuterung: "Ein kleines Paddelboot. Oben hat es ein enges Loch für nur einen Sitz; das Wasser kann dann nicbt so schnell rein." 17

Nur auf diejenigen Aspekte des Beispiels, die ich hier für wichtig halte, gehe ich nun ein. Zunächst ist klar: Es liegt ein partieller Kommunikationskonflikt vor, der durch eine Wissenslücke Bobbys zustande kommt. Diese besteht im wesentlichen darin, daß Bobby einen Gegenstand und daher den semantischen Gebrauch der Gegenstandsbezeichnung nicht kennt. Ich spreche daher von einem semantisch bedingten Kommunikationskonflikt. Wie die Was-ist-Frage Bobbys zeigt, kann er die Äußerung von Matthias deswegen nicht voll verstehen, weil er nicht weiß, was ein Kajak ist; daher weiß Bobby auch nicht, wie Matthias das Wort Kajak semantisch gebraucht, denn er kann nicht nachvollziehen, von welchem Gegenstand und von welcher Art Gegenstand Matthias prädiziert, daß er ein Kajak ist. Das heißt allerdings nicht, daß er aus der Äußerung von 
Matthias gar nichts über Kajaks weiß, denn er hat ja gerade gehört, daß ein Kajak offensichtlich etwas sein muß, das ein Junge zum Geburtstag bekommen kann, und außerdem, daß Matthias seinen Kajak als "toll" bewertet. Aufschlußreich an der Frage Bobbys ist nun, daß er - obwohl er offensichtlich das Wort Kajak nicht voll verstanden hat, nicht nach diesem Wort, der Wortbedeutung oder dem Wortgebrauch fragt, sondern nach dem Gegenstand Kajak; offensichtlich setzt Bobby voraus - und kann dies nach der Außerung von Matthias auch - daß Matthias über einen bestimmten Gegenstand gesprochen hat. Gemäß der Frage Bobbys ist nun die Antwort von Matthias eine zwar nicht vollständige, aber dennoch korrekte ad-hoc-Beschreibung seines Kajaks, die zugleich auf alle Kajaks zutrifft. Der Aufbau dieser Beschreibung ist durchaus für solche isolierten Dingbeschreibungen charakteristisch: Zunächst bestimmt Matthias seinen Kajak dadurch näher, daß er ihn - extensional ausgedrückt - einer Klasse von Gegenständen zuordnet, nämlich der der Paddelboote; oder intensional ausgedrückt : er erklärt Bobby, daß sein Kajak die Eigenschaft hat, ein Paddelboot zu sein. Er setzt daher offensichtlich voraus, daß Bobby weiß, was Paddelboote sind und nur die besondere Art von Paddelbooten, eben die Kajaks, nicht kennt. Daher prädiziert er von seinem Kajak - relativ zu anderen Paddelbootarten oder Booten - noch einige charakteristische Eigenschaften, nämlich, daß er klein ist, oben ein Loch hat, das nur für einen Sitz da ist. 18

Nach Matthias'Antwort hat Bobby etwas über Kajaks gelernt. Aber dieser Lernprozeß bezieht sich nicht nur auf die sprachlich vermittelte Kenntnis eines Gegenstandes mit Namen Kajak, sondern auch auf die Sprache, denn Bobby weiß nun auch - zumindest ungefähr - wie man das Wort Kajak in der Sprache, die sie beide sprechen, semantisch regelgerecht gebraucht. Obwohl also die beiden Jungen ausdrücklich über einen Gegenstand geredet haben, haben sie, indem sie das korrekt getan haben, zugleich einen regelgerechten Wortgebrauch eingeübt. ${ }^{19}$ Die sprachliche Kommunikation über den Gegenstand hat dabei zugleich eine metakommunikative Konsequenz insofern, als Bobby nun auch etwas über den regelgerechten Gebrauch des Wortes Kajak sagen könnte.

lch "experimentiere" nun mit dem gegebenen Beispiel und nehme an, Bobby hätte anstatt direkt nach dem Gegenstand zu fragen, etwa eine der folgenden Fragen gestellt:

\footnotetext{
"Was meinst du mit Kajak?"

"Was beißt denn Kajak?"

"Was bedeutet das Wort Kajak?"

"Was bezeicbnest du mit dem Ausdruck Kajak?"

"Wie gebraucht man denn das Wort Kajak?"
} 
Mit solchen Fragen, (die nach meiner Beobachtung allerdings eher von Erwachsenen gestellt werden), hätte Bobby also direkt nach dem ihm unbekannten Wort, nach der Wortbedeutung oder dem Wortgebrauch gefragt. Auf jede dieser Fragen hätte Matthias durchaus wieder mit einer Beschreibung des Gegenstandes antworten können, weil er - wie wir gesehen haben - damit auch etwas zum regelgerechten Gebrauch des Wortes Kajak gesagt und somit die Frage beantwortet hätte. Er hätte aber auch mit einer Erläuterung des regelgerechten Wortgebrauchs antworten können, z.B. so: "Mit dem Wort Kajak meint man Paddelboote, die...". Bei allen denkbaren Antworten, die als Erläuterung des regelgerechten Gebrauchs des Wortes Kajak gelten können, hätte er aber zugleich etwas Korrektes und Charakteristisches über den Gegenstand Kajak gesagt.

Aufgrund dieses Beispiels möchte ich nun folgende induktive Verallgemeinerung ${ }^{20}$ vornehmen:

(1) Unterhalten sich zwei Personen $P_{1}, P_{2}$ in einer Sprache $L$, und

(a) äußert $P_{1}$ einen usuellen Text ${ }^{21} \mathrm{~T}$ in $\mathrm{L}$, der ein Wort $\mathrm{W}$ enthält, das $P_{2}$ inhaltlich nicht versteht, und

(b) fragt daraufhin $\mathrm{P}_{2} \mathrm{P}_{1}$ nach einem (in einer bestimmten Welt situierten) Gegenstand $G$, von dem $P_{1}$ mit $W$ in $T$ etwas prädiziert (oder: auf den $P_{1}$ mit $W$ in $T$ referiert), und

(c) gibt $\mathrm{P}_{1}$ daraufhin eine korrekte, nicht notwendig vollständige, aber charakteristische sprachliche Beschreibung $B$ in $L$ von $G$, dann

(d) erklärt $\mathbf{P}_{1}$, indem er $\mathbf{B}$ äußert, auch den regelgerechten Gebrauch von $W$ in usuellen $T$ aus $L$, und

(e) damit hat $P_{2}$ nicht nur etwas über $G$, sondern auch etwas über den regelgerechten Gebrauch von $W$ in usuellen $T$ aus $L$ gelernt.

(2) Unterhalten sich zwei Personen $\mathbf{P}_{1}, \mathrm{P}_{2}$ in einer Sprache $\mathrm{L}$, und

(a) äußert $P_{1}$ einen usuellen Text $T$ in $L$, der ein Wort $W$ enthält, das $P_{2}$ inhaltlich nicht versteht, und

(b) fragt daraufhin $P_{2} P_{1}$ nach dem Gebrauch von $W$ in $T$, und

(c) gibt $\mathrm{P}_{1}$ daraufhin eine nicht notwendig vollständige, aber korrekte Erläuterung $E$ in $L$ des regelgerechten Gebrauchs von $W$ in $T$, dann

(d) beschreibt $P_{1}$, indem er $E$ äußert, auch charakteristische Aspekte desjenigen Gegenstandes $G$, von dem er mit $W$ in $T$ etwas prädiziert (oder: auf den er in $\mathrm{T}$ mit $\mathrm{W}$ referiert) hat, und

(e) damit hat $P_{2}$ nicht nur etwas über den regelgerechten Gebrauch von $W$ in usuellen $T$ aus $L$ gelernt, sondern auch etwas - wenigstens über charakteristische Eigenschaften - von G. 
Wenn diese, insbesondere was die konversationellen Voraussetzungen und Bedingungen betrifft, verkürzt wiedergegebene Verallgemeinerung richtig ist, dann folgt daraus, daß es nicht angebracht ist, bei der Herstellung und Analyse von Worterklärungen - und das gilt auch für die lexikalischen Paraphrasen von Lexikographen - zwischen sprachlichen Phänomenen einerseits und Gegenständen des Weltausschnittes, über den mit dem erklärten Wort geredet wurde bzw. geredet werden kann andererseits, st r i k t z u t r e n n e n; das bedeutet natürlich nicht, daß wir nicht jederzeit zwischen sprachlichen Phänomenen, wie z.B. dem Wort Kajak und dem Gegenstand Kajak de u t li c h u n t e r s c h e id e n können. Nur sollte klar bleiben: Daß man Dinge deutlich unterscheiden kann, heißt nicht, daß man sie strikt trennen muß oder kann. Die Herstellung einer lexikalischen Paraphrase des Lemmas Kajak in einem einsprachigen Wörterbuch ist daher nicht möglich ohne eine gewisse Sachkenntnis über Kajaks. Viele Wörterbucheinträge sind daher auch zugleich unvollständige Sachbeschreibungen. Ein einsprachiges Wörterbuch ist daher nie ein Buch, das nur von den Wörtern und ihrem Gebrauch handelt. Wörterbuch und Enzyklopädie (verstanden als Buch über Sachen) können daher zwar unterschieden werden, eine strikte Trennungslinie zwischen beiden gibt es jedoch nicht. ${ }^{22}$ Die Analyse lexikalischer Paraphrasen in einsprachigen Wörterbüchern kann daher nicht bloß mit internsemantischen Kategorien arbeiten.

Kehren wir aber noch einmal zu dem Beispiel Nr. 1 zurück! Im ersten Teil seiner Antwort "Ein kleines Paddelboot..." greift Matthias of fensichtlich auf eine sprachinhaltlich (regelhafte) Beziehung zwischen Wörtern zurück. $\mathrm{Da}$ er weiß - was aus seiner Antwort hervorgeht -, daß alle Kajaks besondere Paddelboote sind, aber umgekehrt nicht alle Paddelboote Kajaks, verfügt er, indem er dieses begriffliche Wissen über bestimmte Dinge der Welt hat, damit auch über eine bestimmte semantische Beziehung der zugehörigen Wörter; diese können wir im Rahmen einer Theorie z.B. als einen Fall der Relation der lexikalischen Hyponymie identifizieren: Kajak ist hyponym zu Paddelboot. ${ }^{23}$ Man sieht demnach: Bei seiner Gegenstandsbeschreibung macht Matthias von einer bestimmten Ähnlichkeitsbeziehung, in der u.a. Wörter zueinander stehen, Gebrauch. Nun heißt seine Beschreibung aber nicht: "Ein Kajak ist ein Paddelboot". Das bedeutet: Matthias hat keine Äußerung gemacht, die lediglich - theoretisch ausgedrückt eine Hyponymierelation ausdrückt. Vielmehr bestimmt er Kajaks noch etwas genauer; seine Antwort ist nämlich so geartet, daß der durch die Hyponymierelation gegebene Ähnlichkeitsgrad zwischen den Wörtern Kajak und Paddelboot durch den Text so erhöht wird, daß die Antwort von Matthias einer lexikalischen Paraphrase des Wortes Kajak in einspra- 
chigen Wörterbüchern sehr nahe kommt. ${ }^{24}$

E und B (vgl. oben (1) (c) und (2) (d)) sind daher usuelle Texte, in denen von inhaltlichen Ähnlichkeitsbeziehungen zwischen Wörtern, die in der Sprache gegeben sind und über die Personen verfügen, Gebrauch gemacht wird. 25

Die synchronischen Wortbedeutungserklärungen, die lexikalischen Paraphrasen der Lexikographen, lassen sich daher m.E. als Systematisierungen derjenigen sprachkommunikativen, insbesondere metakommunikativ-dialogischen Verfahren auffassen, die in alltagssprachlichen Kommunikationsakten dann angewandt werden, wenn es darum geht, partiell semantisch bedingte Kommunikationskonflikte, die durch die Unkenntnis von Wörtern und deren Gebrauch entstanden sind, durch sprachliche Paraphrasierungen in der gleichen Sprache auszuräumen. ${ }^{26}$

Bei diesen Systematisierungen, die nur in einem theoretischen Rahmen möglich sind, spielt - neben Begriffen wie z. B. Hyponymie und Antonymie - besonders der der Synonymie eine wichtige Rolle.

Jeder hinreichende Synonymiebegriff ist ein theoretischer Begriff, definiert relativ zu einer Reihe von anderen Begriffen im Rahmen mindestens einer Teiltheorie. In der bisher geführten - nur schwer überschaubaren neueren Diskussion um den Synonymiebegriff hat sich m.E. herausgestellt, daß folgende Begriffe im Rahmen einer linguistischen Theorie der Synonymie eine zentrale Rolle spielen: Analytizität, Real- und Nominaldefinition, Übersetzbarkeit bzw. Nichtübersetzbarkeit, analytische Implikation, logische Folgerung, logische und semantische Äquivalenz, Äquivalenz- und Toleranzrelation, Austauschbarkeit in extensionalen Kotexten, Ähnlichkeit, Gleichheit, Identität und Identifikation sowie die Unterscheidung von Symbol-, Signal- und Symptomfunktion der Sprache. Einige dieser Begriffe spielen auch eine Rolle, wenn man versucht, einen Synonymiebegriff - im Rahmen der gegebenen Fragestellung - für die einsprachige Lexikographie zu diskutieren. ${ }^{27}$

Wenn Synonymie ein theoretischer Begriff ist, dann folgt daraus mindestens zweierlei:

(1) Synonymiebehauptungen der Form $x$ ist synonym mit $y$ (mit $x, y$ hier und nachfolgend als Variablen für Ausdrücke aus nur e i n e r Sprache $L$ ) können nur angemessen diskutiert werden relativ zu einem bestimmten theoretischen Synonymiebegriff, der mehr ist als lediglich eine sprachliche Etikette für eine beliebige Liste von Ausdrücken einer Sprache L, die a priori als synonym angesehen werden. 
(2) Synonyme und ihre Synonymie oder Synonymität 28 - im Sinne irgendeiner Theorie - sind uns daher als sprachliche Phänomene nicht einfach gegeben; sie zeigen sich uns als synonym nicht einfach in der alltäglichen Sprachpraxis. Wohl aber machen Personen, die eine Sprache L kennen und/oder beherrschen, in der und durch die Kommunikation die Erfahrung, daß zahlreiche Ausdrücke aus L wie z.B. fast und beinabe, obschon und obgleich, Schimmel und weißes Pferd, Resultat und Ergebnis, ledig, unverbeiratet und alleinstebend, Aufzug, Fabrstubl und Lift, Dusche und Brause, Hast und Eile, Scbluß $\mathrm{B}$ und Ende, da und dort, Apfelsine und Orange, Adresse und Anschrift, beginnen und anfangen, Fußball und Leder, Morgenland und Orient etc. häufig inhaltlich sehr ähnlich oder gleich gebraucht werden. Diese sprachpraktische Erfahrung, die auch Sprachwissenschaftler machen (!), bzw. deren mehr oder weniger isolierte Verallgemeinerung zu einem alltagstheoretischen Begriff von inhaltlicher Gleichheit oder Ähnlichkeit von Ausdrücken der je erfahrenen Sprache darf jedoch nicht mit einem wissenschaftlich-theoretischen Begriff von inhaltlicher Gleichheit oder Ähnlichkeit von Ausdrücken einer $\mathrm{zu}$ untersuchenden Sprache verwechselt werden ; ${ }^{29}$ die verallgemeinerte Spracherfahrung in einem alltagstheoretischen Begriff ist vielmehr nur der - wie mir scheint allerdings notwendige - Ausgangspunkt für die theoretische Konstitution eines sprachwissenschaftlichen Synonymiebegriffes.

Wenn nun einsprachige Wörterbücher u.a. in semantisch bedingten Kommunikationskonflikten wirklich nützlich sein sollen, dann sollte ein Synonymiebegriff, an dem sich lexikographische Praxis orientieren kann, offensichtlich nicht so stark sein, daß er z.B. diejenigen Ausdrücke nicht als synonym gelten läßt, die die Mehrzahl der Wörterbuchbenutzer voraussichtlich häufig als inhaltlich gleich oder ähnlich gebraucht erfahren. Daher stellt J.R. Searle - offensichtlich in Richtung W.V. Quine - wenigstens tendentiell zutreffend - fest:

“'Die Behauptung, daß 'Okulist' A ugenarzt bedeutet, muß nicht irgendwelchen von Philosophen vorgeschlagenen Kriterien für Synonymie genügen, sondern umgekehrt jedes vorgeschlagene Kriterium für Synonymie muß mit Tatsachen wie der, daß Augenarzt synonym mit 'Okulist' ist, übereinstimmen." 30

\section{Interpretation der lexikographischen Praxis I. Wörterbucheinträge der Form 'Lemma' Wort}

Im Folgenden versuche ich, ausgewählte Teile der lexikographischen Praxis im Lichte eines Synonymiebegriffes zu interpretieren, von dem ich annehme, daß er denen im vorigen Abschnitt angedeuteten Anforderungen genügt. Dieser Synonymiebegriff wird im Laufe dieser Praxisana- 
lyse selbst schrittweise expliziert, allerdings nicht bis in alle Details und hinsichtlich aller Konsequenzen. Meine Beispiele für Wörterbucheinträge nehme ich aus Wahrigs "Deutschem Wörterbuch". Meine exemplarischen Ausführungen lassen sich daher ohne Modifikationen nur auf Wörterbücher dieses Typs verallgemeinern.

2.1. Zum Verständnis von Bedeutungserklärungen in Wörterbucheinträgen BEISPIEL Nr. 2

Im "Wahrig" findet sich folgender Wörterbucheintrag :

'Veterinär' Tierarzt

Hinter dem (halbfett gedruckten) Lemma 'Veterinär' steht kursiv gedruckt Tierarzt. 31 "Kursivdruck [steht] für die Bedeutungserklärungen". $32 \mathrm{Be}$ deutungserklärung ist - im Falle von Wörterbucheinträgen der Form 'Lemma' Wort - Wahrigs Ausdruck für lexikalische Paraphrase. Aufgrund der metakommunikativen Funktion der Schrifttypen in einem Wörterbuch, die Wahrig explizit erläutert, weiß demnach der Wörterbuchbenutzer: Tierarzt ist die Bedeutungserklärung für 'Veterinär'.

Was kann das aber genau heißen?

Richten wir die Frage zunächst an Wahrigs Wörterbuch! Hier findet sich in den "Hinweisen für die Benutzung" auch ein Abschnitt, überschrieben: "Die Anordnung der Wortklärungen und der Aufbau eines Wörterbuchartikels". Dort heißt es u.a.:

"Bei den Worterklärungen handelt es sich also immer darum, Hilfen zu geben, die es dem Benutzer ermöglichen, durch ihm bekannte sprachliche Elemente andere ihm unbekannte zu erschließen [...]"33

M.E. greifen diese Ausführungen zu kurz. Denn was unter einer Wortbedeutungserklärung innerhalb eines Wörterbucheintrages genau zu verstehen ist und wie solche Bedeutungserklärungen vom Wörterbuchbenutzer zu lesen und genau zu verstehen sind, wird dem Benutzer nirgends explizit gesagt. Auch in dem vorangestellten "Lexikon der deutschen Sprachlehre" findet man keine Stichworte 'Bedeutungserklärung' oder 'Wortbedeutungserklärung' ; man findet aber das Stichwort 'Wortbedeutung' und unter diesem heißt es:

"Jedes Wort hat seine Bedeutung, aber die Bedeutung vieler Wörter ist nicht einheitlich und ergibt sich jeweils aus dem Zusammenhang, in dem es gebraucht wird". ${ }^{34}$

In Wahrigs Wörterbuch wird nun Veterinär im Zusammenhang 'Veterinär' Tierarzt gebraucht: die Bedeutung kann sich also nur aus Tierarzt ergeben. Auch auf diesem Wege kommt man demnach zu dem Ergebnis: 
Tierarzt erklärt die Bedeutung von 'Veterinär'. Oder weniger hypostasierend ausgedrückt: Mit Tierarzt erklärt der Lexikograph dem jeweiligen Wörterbuchbenutzer die Bedeutung von 'Veterinär'.

Wie ist das aber mittels einer solchen Bedeutungserklärung als Ergebnis eines Schreibaktes möglich?

Da uns Wahrigs Wörterbuch darüber keine nähere Auskunft gibt, richten wir diese Frage an die Arbeiten, in denen Wahrig seine lexikographische Praxis erläutert hat. Aus diesen ergibt sich: Unter einer Bedeutungserklärung versteht Wahrig - wie zahlreiche andere Autoren auch ${ }^{35}$ - eine besondere (etwas merkwürdige) Form von Definition, die lexikographische oder Wörterbuchdefinition heißt. Über diese schreibt Wahrig:

"A ufgabe unserer Definition is t es [...] praktisch: die unbekannte Bedeutung eines Wortes durch Wörter mit bekannter Bedeutung zu erklären [...]. Im einsprachigen Wörterbuch haben wir es also mit Realdefinitionen zu tun, deren Extension, also deren Geltungsbereich, empirisch festgestellt und demnach als Konvention im Bereich der natürlichen Sprachen aufgefaßt wird (A.J. Ayer $1936,161955: 70$ ): 'Thus, in specifying the language to which he intends his definitions to apply, the philosopher is simply describing the conventions from which his definitions are deduced; and the validity of the definitions depends solely on their compatibility with these conventions' ".36

Ich kann dies nur so verstehen: Die Extension des Definiendum 'Veterinär' ist gleich der Extension des Definiens Tierarzt, weil mit empirischer Gültigkeit (Wahrheit) behauptet werden kann, daß in einer bestimmten Welt, nämlich in der "Realität, in der wir leben" 37 , alle Veterinäre Tierärzte sind und umgekehrt; daraus ergibt sich dann für den regelgerechten Gebrauch von Tierarzt, daß er aus dem regelgerechten Gebrauch von Veterinär gefolgert werden kann. Wir sehen also, daß bei diesem Verständnis der anhand des Beispiels Nr. 1 explizierte Zusammenhang zwischen Beschreibung des Gegenstands und Erläuterung des Wortgebrauchs wieder erkennbar wird. Obwohl die lexikographische Definition hier also als eine Realdefinition aufgefaßt wird, kann sie auch - aufgrund sprachlicher Konventionen - als (semantische) Nominaldefinition aufgefaßt werden. ${ }^{38}$

Wir können also nach dieser Auffassung sagen: Tierarzt definiert 'Veterinär', auf die Satzform gebracht demnach: $y$ definiert $x$, mit $x$ als Variable für Lemmata (= Definienda) und $y$ als Variable für Definientes aus gerade einem Wort. Zu erwähnen ist noch, daß das "Erschließen" von unbekannten sprachlichen Elementen und Wortbedeutungen, von dem Wahrig spricht, wohl nicht allein aufgrund der isolierten Kenntnis des bekannten Wortes im jeweiligen Definiens möglich ist. Vielmehr muß das Prädikat "bekannt" so aufgefaßt werden, daß z.B. im Falle von Tierarat der Benutzer bereits Tierarzt richtig gebrauchen, also korrekte Texte mit Tier- 
arzt bilden und verstehen kann. Deshalb wird später zu fragen sein, welche Art von Texten das insbesondere sein können.

Die in der Satzform $y$ definiert $x$ zum Ausdruck kommende Leseart von Wörterbucheinträgen der Form 'Lemma' Wort ist zwar etwas eigenartig, einen Vorteil jedoch hat sie: Sie schließt eine, in der Semantik öfters anzutreffende Leseart aus, nämlich: Veterinär hat die Bedeutung "Tierarzt". Das auffallende an dieser Leseart sind die als semiotische Ganzheit aufzufassende Anführungszeichen ${ }^{39}$, in denen Tierarzt steht. Man kann sie in verschiedener Weise auffassen; zwei Varianten seien genannt: ${ }^{40}$

(1) Die Anführungszeichen lassen sich als diakritisches Symbol verstehen, das metakommunikativ anzeigt, daß Tierarzt in Anführungszeichen, also "Tierarzt", nicht als das Wort Tierarzt, sondern als eine Bedeutung von einem anderen Wort, nämlich Veterinär aufzufassen ist. Man sieht, daß bei einem solchen Verständnis der Anführungszeichen diese Leseart leicht dazu führen kann, Wortbedeutungen zu hypostasieren.

(2) Die Anführungszeichen lassen sich als eine besondere Art von Operator auffassen, der Wörter - hier Tierarzt - einer besonderen Klasse von Bezeichnungen zuweist, nämlich solchen, die Bedeutungen von anderen bilateralen Wörtern bezeichnen oder ausdrücken. In diesem Falle wäre die Leseart: Veterinär hat die Bedeutung "Tierarzt" zu verstehen als: Veterinär hat die Bedeutung, die mit Tierarzt bezeichnet oder ausgedrückt wird. Man sieht, daß ein solches Verständnis der Anführungszeichen dazu führt, Tierarzt in Anführungszeichen, also "Tierarzt, als lexikographische Metasprache zu Veterinär aufzufassen.

Nun können wir aber offensichtlich unter Benutzung der Anführungszeichen sagen:

Ve te rinär bat die Bedeutung "Tierarzt"
Ti e rarz $t$ bat die Bedeutung "Veterinär"

Daher können wir (1) und (2) einfach als Verkürzungen auffassen von

$$
V \text { e t e rinär bat die gleiche Bedeutung wie Tierarz } t
$$

Zwischen (1), (2) einer- und (3) andererseits besteht nun der Unterschied, $\mathrm{da} ß$ in (3) die Anführungszeichen verschwunden sind; d.h. in unserem $\mathbf{Z u}$ sammenhang: man hat erstens eine Klasse von Bezeichnungen weniger und man hat zweitens die Bedeutung nicht mehr - tendentiell wie ein Ding - in Anführungszeichen fixiert, sondern in (3) wird von der Auffassung ausgegangen, daß man Zugang zu den Bedeutungen von Veterinär und Tierarzt nur über ihren Vergleich hat, der in (3) daher als eine Behauptung über eine Bedeutungsrelation in der Form eines Behauptungs- 
satzes ausgedrückt ist.

Setzen wir nun für bat die gleicbe Bedeutung wie in (3) ist synonym mit, erhalten wir:

$$
\text { Veterinär ist synonym mit Tierarzt }
$$

Dies a uf die Satzform gebracht, ergibt $x$ ist synonym mit $y$.

Wie hängen nun die beiden Satzformen $y$ definiert $x$ und $x$ ist synonym mit $y$ miteinander zusammen?

Bei seinem Versuch, den Begriff der Analytizität zu "klären", stößt W.V. Quine über den Zusammenhang von Analytizität und Synonymität auch auf den von Synonymität und Definition. Er schreibt:

"Manche finden es beruhigend, daß die analytischen Aussagen der zweiten Klasse [z.B. Kein Junggeselle ist verbeiratet] auf die ersten, auf die logischen Wahrheiten, durch Definition zurückführbar sind. 'Junggeselle' wird beispielsweise als 'unverheirateter Mann' definiert. Wie aber kommen wir darauf, daß 'Junggeselle' als 'unverheirateter Mann' zu definieren ist? Wer definiert ihn so und wann? Berufen wir uns auf das nächste Wörterbuch und anerkennen wir die Formulierung des Lexikographen als Gesetz? Das würde offenbar bedeuten, den Wagen vor das Pferd zu spannen. Der Lexikograph ist ein empirischer Wissenschaftler, dessen Geschäft in der Aufzeichnung vorgegebener Tatsachen besteht. Und wenn er 'Junggeselle' mit 'unverheirateter Mann' erklärt, dann liegt dem sein Glaube zugrunde, daß es eine Beziehung der Synonymität zwischen jenen Formen gibt, die im allgemeinen im für sein eigenes Werk bevorzugten Gebrauch unausdrücklich enthalten ist. Der Begriff der Synonymität, der hier vorausgesetzt wird, muß noch geklärt werden, und zwar vermutlich in bezug auf das sprachliche Verhalten. Sicherlich kann die 'Definition', die die lexikographische Angabe einer beobachtbaren Synonymität ist, nicht als die Ursache für die Synonymität angesehen werden." 41

Schließlich stellt Quine fest - nachdem er die "ausdrücklich vereinbarte Einführung von neuen Bezeichnungen zum Zwecke bloßer Abkürzung" 42 als einen Fall betrachtet, in dem die Synonymität durch eine Definition allererst geschaffen wird:

"Es wäre schön, wenn alle Arten der Synonymität so verständlich wären. Für die übrigen gilt, daß die Definition eher auf der Synonymität beruht als daß sie sie erklärt." 43

Wenn wir Quine zustimmen können, daß die Synonymität eher die Definition erklärt als umgekehrt, dann scheint es mir zweckmäßig zu sein, auch innerhalb der Lexikographie anstelle einer Definitionsrelation eher eine Synonymierelation zwischen Lemma und Bedeutungserklärung anzunehmen.

Setzen wir in die bisher behandelten Satzformen das Wortpaar Krankenbaus, Hospital ein, dann ergibt sich: 
(5) Hospit al bat die Bedeutung "Krankenhaus"

(6) Hospital ist synonym mit Krankenbaus

(4) und (5) lassen sich auf (6) zurückführen.

2.2. "Wörterbuchdefinitionen" als verkürzte Behauptungen über Bedeutungsrelationen

Nach meiner bisherigen Argumentation scheint es mir gerechtfertigt, hier auf den Begriff der lexikographischen oder Wörterbuch-Definition zu verzichten und stattdessen Wörterbucheinträge der Form 'Lemma' Wort als Behauptungen von Lexikographen über Bedeutungsrelationen aufzufassen. ${ }^{44}$ Unter Behauptung verstehe ich hier nicht den Akt des Behauptens, sondern dessen (Äußerungs)-Resultat, die gemachte Behauptung, die sich in einer bestimmten Form - graphisch oder phonisch - manifestiert, und zu einer bestimmten grammatischen Kategorie, z.B. einem Behauptungssatz, gezählt werden kann, und die von dem zu unterscheiden ist, was in der gemachten Behauptung behauptet ist; was behauptet ist, kann Proposition genannt werden. ${ }^{45}$

An den Wörterbucheinträgen interessiert hier die gemachte Behauptung und das, was in ihr behauptet ist. Die gemachte Behauptung nun hat offensichtlich nicht die Form eines Behauptungssatzes; das läßt sich auf praktische Erwägungen zurückführen, die in der Geschichte der Lexikographie zur Tradition geworden sind. Daß keine Äußerungsresultate vorliegen, die zur Klasse der Behauptungssätze gezählt werden können, spricht jedoch nicht dagegen, daß als Resultat eines lexikographischen Schreibaktes eine Behauptung vorliegt, in der etwas behauptet wird. In unserem Beispiel 'Veterinär' Tierarzt ist daher behauptet, daß Veterinär zu Tierarzt in einer bestimmten semantischen Ähnlichkeitsbeziehung steht, die ich hier vorläufig Synonymie nenne.

Wörterbuchbenutzer, die in die kulturelle Praxis des Wörterbuchbenutzens eingeübt sind, wissen normalerweise mehr oder weniger genau, daß der Wörterbucheintrag 'Veterinär' Tierarzt etwa das gleiche besagen soll wie das, was mit einem der folgenden Behauptungssätze zum Ausdruck gebracht wird:

(7) Veterinär bat die gleicbe Bedeutung wie Tierarzt

(8) Veterinär bat eine äbnliche Bedeutung wie Tierarzt

(9) Veterinär wird wie Tierarzt gebraucht 
Wörterbucheinträge der Form 'Lemma' Wort lassen sich daher verstehen als verkürzte kategorische Behauptungssätze, in denen ein bestimmtes Wissen über den regelgerechten Gebrauch einer kodifizierten Sprache uneingeschränkt ausgedrückt wird. Ich gehe daher im Folgenden davon aus, daß der Wörterbucheintrag 'Veterinär' Tierarzt sich als syntaktisch verkürzte Form für den Behauptungssatz

\section{(10) Veterinär ist synonym mit Tierarzt}

auffassen läßt, zumindest aber davon, daß in dem Wörterbucheintrag das gleiche behauptet ist wie in (10).

Die eben vorgeschlagene Auffassung zeigt m. E. auch deutlicher als andere, daß bezüglich Wörterbucheinträgen der Form 'Lemma' Wort die Frage nach der Wahrheit nicht von vornherein sinnlos oder unangemessen sein muß. Natürlich soll nicht behauptet werden, daß der Wörterbucheintrag 'Veterinär' Tierarzt ein wahrheitsfähiges sprachliches Gebilde im Sinne der Logik oder der Philosophie ist. Es läßt sich aber die Frage stellen: Stimmt der Wörterbucheintrag 'Veterinär' Tierarzt eigentlich? Oder entsprechend: Ist (10) wahr?

Diese Fragen können kaum beantwortet werden ohne ein gründlicheres Wissen über den Status von Wörterbucheinträgen. So läßt sich z.B. die Frage nach der Wahrheit von (10) nicht beantworten ohne ein genaueres Verständnis des Ausdruckes ist synonym mit, da man anderenfalls gar nicht weiß, was eigentlich genau mit (10) behauptet ist. Wir müssen daher auf die Frage nach der Wahrheit später noch einmal zurückkommen. ${ }^{46}$

\subsection{Lesearten des Relationsausdruckes ist synonym mit}

Nun muß daher offensichtlich gefragt werden: Was ist in (10) eigentlich genau behauptet? Das bedeutet: Es muß geprüft werden, welches Verständnis des Relationsausdruckes ist synonym mit in dem hier vorgegebenen Fragerahmen begründet als angemessen vorgeschlagen werden kann.

\subsubsection{Erste Leseart: Logische Äquivalenz}

Ein Verständnis als "ist logisch äquivalent mit" im Sinne der extensionalen Logik fällt von vornherein aus. Denn da es hier um die Bedeutung der Synonymierelation für die Lexikographie geht, ist klar, daß als Vorbereich der Relation nur eine Menge von Lemmata infrage kommt. Zwar können im Nachbereich der Relation auch Sätze auftreten, aber es gibt natürlich auch keinen Sinn, nach der logischen Äquivalenz eines Lemmas mit einem Satz zu fragen. 


\subsubsection{Zweite Leseart: Bedeutungsgleichheit mit verschiedenen Gleichheitskriterien}

Versuchen wir es nun mit einem Verständnis des Relationsausdruckes im Sinne von "ist bedeutungsgleich mit". Da es uns hier um Wörterbucheinträge der Form 'Lemma' Wort geht, lassen wir sowohl im Vor- als auch im Nachbereich der Relation zunächst nur Wörter zu. Dann benötigen wir offensichtlich zum Verständnis ein Kriterium für die Gleichheit von Wortbedeutungen.

\subsubsection{Ein Gleichheitskriterium für Wörter: Austauschbarkeit in allen extensionalen Kotexten}

Wenn schon von Gleichheit von Wortbedeutungen die Rede ist, dann scheint es gerechtfertigt, unter den bekannten ein starkes Kriterium auszuwählen. Schließen wir zunächst alle intensionalen Kotexte, d.h. solche Sätze, in denen Ausdrücke nicht salva veritate substituiert werden können, aus ${ }^{47}$ und fordern als Kriterium für eine - als substitutiv zu qualifizierende 48 - Synonymie von Wörtern der gleichen Sprache ihre Austauschbarkeit in allen extensionalen Kotexten dieser Sprache, ohne daß sich die (intensionale) Kotextbedeutung ändert, d.h. genauer: die Ersetzung der Wörter führt zu (intensional) bedeutungsgleichen Kotexten ohne Wahrheitsgehaltsänderung. Der Überschaubarkeit halber nehmen wir als Kotexte Sätze, z.B. folgende :

\section{(11) Hans telephoniert mit dem Veterinär}

(12) Hans telephoniert mit dem Tierarzt

Sind nun die Sätze (11) und (12) bedeutungsgleich?

$\mathrm{Da}$ diese Frage überhaupt gestellt werden muß, zeigt schon, daß das gewählte Kriterium für die Gleichheit von Wortbedeutungen die Entscheidung über die Gleichheit nur verschiebt, und zwar in unserem Beispiel auf die Beurteilung von Sätzen.

\subsubsection{Gleichheitskriterien für Sätze}

Wir brauchen nun also ein Kriterium, nach dem wir die Bedeutungsgleichheit von Sätzen entscheiden können. Zahlreiche Kriterien sind vorgeschlagen worden. Für W.P. Alston z.B. sind zwei Sätze bedeutungsgleich genau dann, wenn sie das gleiche illokutionäre Aktpotential haben; in diesem Fall benötigt man dann ein (von Alston nicht geliefertes) Kriterium, um über die Gleichheit des illokutionären Aktpotentials zweier Sätze entscheiden zu können. ${ }^{49}$ 
Bei der Suche bzw. Festlegung eines Kriteriums für die als Gleichheit verstandene Synonymität von Sätzen oder Ausdrücken aus Sätzen spielt bei zahlreichen Autoren der (bzw. ein) Begriff von Implikation eine zentrale Rolle, und zwar insofern als er als zentraler Begriff im Definiens von Synonymiedefinitionen auftaucht. Die derzeit bekannteste Definition dieses Typs dürfte die von J. Lyons sein. ${ }^{50}$ Sie lautet folgendermaßen:

"If one sentence, $S_{1}$, implies another sentence, $S_{2}$, and if the converse also holds, $S_{1}$ and $S_{2}$ are equivalent: i.e. if $S_{1} \supset S_{2}$ and if $S_{2} \supset S_{1}$, then $S_{1} \equiv S_{2}$ ( where $\equiv$ stands for 'is equivalent to'). If now the two equivalent sentences have the same syntactic structure and differ from one another only in that where one has lexical item, $x$, the other has $y$, then $x$ and $y$ are synonymous." 51

Diese Definition steht und fällt mit dem Begriff der Implikation, den Lyons verwendet. Da "Implikation" zu denjenigen Begriffen gehört, die neuerdings öfters dazu benutzt werden, semantische Probleme zu "lösen" derart, daß sie zugedeckt werden ${ }^{52}$, schiebe ich nun einen Exkurs zum Begriff der Implikation bei Lyons ein.

\subsubsection{Exkurs zum Implikationsbegriff bei Lyons}

Lyons schreibt in einem Abschnitt, der mit " 'Analytische' und 'synthetische' Implikation" überschrieben ist, folgendes:

"Sinnrelationen können in einem System aufgezeigt werden, in dem der Begriff der Implikation einen Platz hat. Dieser Begriff kann hier auf der Grundiage der früher verwendeten Begriffe der expliziten Affirmation (Feststellung) und Negation eingeführt werden. Wir wollen die Annahme treffen, daß es in allen Sprachen möglich ist, Entsprechungsregeln zwischen feststellenden und negierenden Sätzen aufzustellen, und daß weiter die Entsprechung zwischen einem bestimmten feststellenden und einem bestimmten negierenden Satz in der Grammatik der Sprache eine Erklärung findet. So entspricht der negative Satz Jobn ist nicht verbeiratet der Feststellung Jobn ist verbeiratet. Wir sagen nun, daß ein negativer Satz explizit verneint, was der entsprechende feststellende (affirmative) Satz explizit bebauptet (feststellt). Auf der Grundlage dieses Begriffs von expliziter Behauptung und Verneinung können wir den semantisch interessanteren Begriff der impliziten Behauptung und Verneinung oder der Implikation aufbauen. Man sagt, daß ein Satz $S_{1}$ einen anderen Satz $S_{2}$ impliziert - symbolisch $S_{1} \supset S_{2}$-, wenn Sprecher der Sprache darin übereinstimmen, daß es nicht möglich ist, $S_{1}$ explizit zu behaupten und $S_{2}$ explizit zu verneinen. $S_{1}$ wiederum verneint implizit $S_{2}-S_{1}$ impliziert nicbt $S_{2}: S_{1} \supset \sim S_{2}$, wenn nach Obereinkunft die explizite Feststellung von $S_{1}$ die explizite Feststellung von $S_{2}$ ohne Widersprüchlichkeit unmöglich macht." 53

Da es in meiner anschließenden Argumentation um den genauen Wortlaut geht, zitiere ich auch noch das englische Original und numeriere dort die Sätze laufend, so daß ich mich genau darauf beziehen kann. 
" [1] Sense-relations are stateable within a framework which includes the notion of implication. [2] This notion may be introduced here by way of the prior concepts of explicit assertion and denial. [3] We will assume that in all languages it is possible to establish rules of correspondence between affirmative and negative sentences; and that the correspondence between a particular affirmative and a particular negative sentence is accounted for by the grammar of the language. [4] Thus the negative sentence Jobn is not married corresponds to the affirmative sentence Jobn ist married. [5] We will now say that a negative sentence explicitly denies whatever is explicitly asserted by the corresponding affirmative sentence; and on the basis of this notion of explicit assertion and denial we can construct the semantically more interesting notion of implicit assertion and denial, or implication.

[6] One sentence, $S_{1}$, is said to imply another, $S_{2}-$ symbolicaly, $S_{1} \supset S_{2}-$ if speakers of the language agree that it is not possible to assert explicitly $S_{1}$ and to deny explicitly $S_{2}$. [7] And $S_{1}$ implicitly denies $S_{2}-S_{1}$ implies not $S_{2}: S_{1} \supset \sim$ $S_{2}$ - if it is agreed that the explicit assertion of $S_{1}$ makes impossible, without contradiction, the explicit assertion of $S_{2}$."54

Meine zunächst anschließende Argumentation zielt darauf ab zu verdeutlichen, daß es nur scheinbar möglich ist, Sinnrelationen (= Bedeutungsrelationen), also auch die Synonymierelation, zwischen natürlichsprachlichen Ausdrücken ausschließlich über Beziehungen zwischen Sätzen und zugleich intersemantisch, also sprachimmanent, zu definieren, und daß dieser Schein e r s t e n s durch ungenaue Ausdrucksweise bei Lyons, $\mathrm{z}$ w e i t e $\mathrm{n}$ s durch einen unkontrollierten Wechsel zwischen pragmatischen, semantischen und logischen Gesichtspunkten und drittens durch nichtgenannte Voraussetzungen zustande kommt. 55

Zunächst ist unklar, was mit "framework" (System? ) [1] gemeint sein kann, und daß dies unklar bleibt ist - wie zu zeigen sein wird - symptomytisch. Dann werden die Begriffe "explicit assertion" [2] (explizite Affirmation, oder Feststellung, oder auch Behauptung) und "explicit denial" [2] (explizite Verneinung) genannt; ich spreche im Folgenden von $B e$ bauptung und bebaupten bzw. von expliziter Bebauptung und explizit bebaupten; meine Argumentation ändert sich aber inhaltlich nicht, wenn Feststellung, feststellen usw. dafür substituiert werden.

Nach den ersten beiden Sätzen ( [1], [2]) bleibt vorerst unentschieden, ob mit Bebauptung (a) der sprachliche Akt des Behauptens, oder (b) das, was behauptet ist, oder (c) das konkrete sprachliche Resultat eines Behauptungsaktes, z.B. eine geäußerter Behauptungssatz, oder (d) eine linguistische Abstraktion, der Behauptungssatz (z.B. als syntaktische Kategorie) gemeint ist. Entsprechendes gilt für "denial" [2] (Verneinung), mit der Einschränkung, daß das, was verneint ist, (b'), wohl nicht die Verneinung (sondern wiederum Behauptung) genannt werden kann. Sodann werden die Begriffe "affirmative sentence" [ 3] (behauptender Satz) und "negative sentence" [3] (negierender, verneinender Satz) genannt. 
Hier nun ist bemerkenswert, daß nicht von "utterance", sondern von "sentence" gesprochen wird; das bedeutet: es handelt sich nicht um geäußerte Sätze (= Satzäußerungen). ${ }^{55}$ Lyons ist hier relativ zu einer Textstelle vorher konsequent. Dort heißt es:

" [...] wir [können] uns aufgrund einer rein methodologischen Entscheidung einer bei den Linguisten allgemein verbreiteten Praxis anschließen und die semantischen Beziehungen zwischen Äußerungen so betrachten, als handele es sich um die semantischen Beziehungen zwischen den Sätzen, von denen man sich die Äußerungen 'abgeleitet' denkt, wenn sie von muttersprachlichen Sprechern in eingeschränkten Kontexten erzeugt werden." 57

Den oder einen grammatischen Begriff des Satzes kann man durch schrittweise Abstraktion aus dem pragmatischen Begriff der Satzäußerung gewinnen. Auf der Abstraktionsebene der Grammatik sind dann 'behauptende Sätze" solche, denen man aufgrund ihrer grammatischen Struktur ansehen kann, $d$ a $\beta$ mit ihnen, wenn sie in einem Behauptungsakt geäußert werden, etwas behauptet werden kann.

Manchen Sätzen kann man auch ansehen, w a s mit ihnen eventuell behauptet werden kann, z.B. folgendem Beispielsatz von Lyons

(13) Jobn ist verbeiratet (Jobn is married)

Versteht man Deutsch bzw. Englisch, dann weiß man, daß man mit dem deutschen und dem englischen Satz, wenn man ihn äußert, u.a. etwas Angebbares behaupten kann, und zwar das gleiche, nämlich daß John verheiratet ist. ${ }^{58}$ Obwohl man einem Behauptungssatz ansehen kann, was mit ihm behauptet werden kann, weiß man über dasjenige, was behauptet werden kann, nichts Bestimmtes, in dem Sinne, daß man sich nicht zwischen möglichen Bewertungen entscheiden kann. Da nämlich ein isolierter abstrakter Satz (als Gegenstand z.B. der Grammatik) sich von sich aus auf nichts bezieht, kann man z.B. nicht angeben, ob das, was damit behauptet werden kann, eine Tatsache ist oder nicht, oder anders ausgedrückt : ob die Satzproposition entweder wahr oder falsch ist.

In dem nun folgenden Satz [5] unterscheidet nun Lyons auch zwischen einem behauptenden Satz einerseits und dem, was damit behauptet ist andererseits. Sehen wir uns aber genau an, wie diese Unterscheidung eingeführt wird. Es heißt:

"We will now say that a negative sentence explicitly denies whatever is explicitly asserted by the corresponding affirmative sentence" [5]. (Wir sagen nun, daß ein negativer Satz explizit verneint, was der entsprechende behauptende (feststellende, affirmative) Satz explizit bebauptet". 59

Ein Satz - und nicht eine Person mit einem geäußerten Satz - behauptet bzw. verneint etwas explizit. Nach Lyons verneint also der negative Satz 
(13a) Jobn ist nicht verbeiratet explizit dasjenige, was der entsprechende behauptende Satz (13) John ist verbeiratet explizit behauptet. Wie aber machen das diese Sätze? Zeigt es sich an diesen Sätzen oder zeigen uns diese Sätze als Sätze, auf welche Person der Personenname sich als Personenname bezieht? M.E. ist diese Frage nicht nur für die Sätze (13) und (13a), sondern für alle entsprechenden Sätze einer natürlichen Sprache mit Personen-Vornamen zu verneinen. Die Argumentation von Lyons stimmt daher nur dann, wenn der Leser stillschweigend bereit ist, der Personennamen Jobn auf ein und dieselbe Person zu beziehen und somit wenigstens die Koreferenz von (13) und (13a) voraussetzt oder anders ausgedrückt, wenn er bereit ist, die Sätze (13) und (13a) als geäußerte Sätze (= Satzäußerungen) bezogen auf eine bestimmte Situation zu denken, um damit die oben erwähnte methologische Entscheidung von Linguisten tendentiell rückgängig zu machen. Dazu ist der Leser im Allgemeinen bereit, zumal er aus der alltäglichen Kommunikationspraxis gewohnt ist, daß, wenn ein bestimmter Personenname (insbesondere ein Vorname), z. B. in einem Gespräch, gebraucht wird, dieser Name stets auf ein und dieselbe Person bezogen wird; anderenfall wird dies normalerweise ausdrücklich kenntlich gemacht. - Wenn aber Sätze wie z.B. (13) und (13a) im Rahmen einer wissenschaftlichen Argumentation als Beispiel für Sätze gebraucht werden, ist man e $\mathrm{r} \mathrm{s}$ e $\mathrm{n} \mathrm{s}$ nicht genötigt, sie überhaupt auf irgendetwas zu beziehen, und $\mathrm{z}$ w e it e $\mathrm{n} s$, wenn man sie als geäußerte Sätze denkt, braucht man sie dann nicht auf das gleiche Referenzobjekt, hier also auf ein und dieselbe Person, zu beziehen, wenn das nicht e $\mathrm{x}$ $\mathrm{press}$ is ver b is ver la $\mathrm{ng} \mathrm{t}$ ist. Dies ist bei Lyons nicht der Fall, d.h. bestimmte Voraussetzungen sind nicht genannt. Diese könnten zwar in dem Lyon'schen Begriff des "restricted context" (eingeschränkter Kontext ${ }^{60}$, relativ zu dem alle Sinnrelationen (= Bedeutungsrelationen) bei Lyons definiert werden, versteckterweise enthalten sein; aber dieser $\mathrm{Be}$ griff ist derart allgemein und ungenau gefaßt, daß dies nicht sicher auszumachen ist. Damit aber erweist sich die Lyon'sche Argumentation als inkorrekt, wie folgendes Beispiel zeigt:

BEISPIEL Nr. 3

Sei die Person A der Autor des Buches "Introduction to Theoretical Linguistics" mit Namen John Lyons, und sei die Person B der ermordete ehemalige Präsident der U.S.A. mit Namen John F. Kennedy. Ich "spreche" jetzt über die Person A, indem ich einen Behauptungsakt mache und schriftlich (13) äußere: "John is married". Jetzt spreche ich über die Person B und äußere schriftlich (13a): "Jobn is not married". 
Nun gilt of fensichtlich von den von mir behaupteten Sätzen "(13)" und "(13a)" nicht mehr - in der Sprechweise von Lyons ausgedrückt daß der negative Satz (13a) dasjenige explizit verneint, was der grammatisch entsprechende behauptende Satz (13) explizit behauptet.

Wenn die Argumentation von Lyons daher innerhalb des vorgegebenen Rahmens korrigiert werden soll, muß wenigstens eine der drei nachfolgend genannten Voraussetzungen (a) bis (c) angegeben werden:

(a) Über die Ausdrücke in der Nominalphrase und/oder über satzinterne Indikatoren sind die behauptenden oder verneinenden Sätze auf ein und dasselbe Referenzobjekt in der gleichen Situation zu beziehen. ${ }^{61}$ Diese Voraussetzung ist nur in einer Referenztheorie als semantische Theorie des Sachbezugs von sprachlichen Ausdrücken oder innerhalb einer pragmatischen Theorie explizierbar, in der der Akt des Referierens als einer unter anderen sprachlichen Akten oder als Aktaspekt bestimmter Sprechakte erklärt wird.

(b) Die Sätze stehen in einem Kotext, aus dem wenigstens ihre Koreferenz ersichtlich ist. Dies kann auch ein Kotext aus einem eingeschränkten Kontext im Sinne von Lyons sein. Diese Voraussetzung ist nur textlinguistisch explizierbar. ${ }^{62}$

(c) Die Sätze werden nur als Kandidaten für eine Ubersetzung in z. B. eine prädikatenlogische Sprache betrachtet. Diese Voraussetzung kann nur in einer Úbersetzungstheorie expliziert werden, in der eine natürliche Sprache als Ausgangs- und eine prädikatenlogische Konstruktsprache $\mathrm{K}$ als Zielsprache auftreten. ${ }^{63}$

Im nächsten Schritt nun führt Lyons seinen Begriff von Implikation als "implicit assertion" [5] (implizite Behauptung) bzw. "implicit denial" [5] (implizite Verneinung) ein. Es heißt:

"Man sagt, daß ein Satz $S_{1}$ einen anderen Satz $S_{2}$ impliziert - symbolisch $S_{1} \supset S_{2}$, wenn Sprecher darin übereinstimmen, daß es nicht möglich ist, $S_{1}$ explizit zu behaupten und $S_{2}$ explizit zu verneinen" (Übers. von [6] ) 64

Diese Argumentation scheint mir nun in mehrfacher Hinsicht inkorrekt zu sein. In der zitierten Textpartie sind es nun nicht - wie im ersten Teil von [5] - die Sätze, z.B. $S_{1}, S_{2}$, die etwas behaupten bzw. verneinen, sondern die Sprecher der Sprache sollen beurteilen, o b e $s$ mög l i c h is t (!), einen Satz $S_{1}$ explizit zu behaupten und einen anderen Satz $S_{2}$ explizit zu verneinen. Das kann offensichtlich nur so verstanden werden, daß die Sprecher in eventuellen Urteilen darin übereinstimmen sollen, ob es möglich ist, in Behauptungsakten diese Sätze $S_{1}, S_{2}$ zu äußern; und wenn dies nun - nach 
übereinstimmenden Urteilen von Sprechern - nicht möglich ist, dann impliziert der Satz $S_{1}$ den Satz $S_{2}$, und dies wird symbolisiert als $S_{1} \supset S_{2}$. Was soll aber heißen, ob es möglich bzw. nicht möglich ist? Nehmen wir folgendes Beispiel!

BEISPIEL Nr. 4

Ich führe nun nacheinander zwei Behauptungsakte aus, indem ich die Sätze (14) und (15) schriftlich äußere:

(14) "Jobn zeichnet ein Quadrat"

(15) "Jobn zeichnet kein Viereck"

(15) ist die verneinte grammatische Entsprechung - Lyons würde sagen die explizite Verneinung von

(14a) Jobn zeicbnet ein Viereck

(14) setzen wir nun für $S_{1}$ und (14a) für $S_{2}$ ein. Dann zeigt das Beispiel, daß es möglich, weil im Beispiel geschehen, ist, einen Satz $S_{1}$ explizit zu behaupten und zugleich einen anderen $S a t z S_{2}$ explizit zu verneinen, und daß trotzdem der Satz $S_{1}$, hier also (14), den Satz $S_{2}$, hier also (14a), impliziert, obwohl das nach Lyons nur dann der Fall sein soll, wenn das, was im Beispiel Nr. 4 geschehen ist, nicht möglich ist.

Lyons muß demnach etwas anderes gemeint haben. Eventuell klärt sich, was er gemeint hat, wenn wir das "without contradiction" aus dem darauf folgenden Satz [ 7 ]', das terminologisch so unverbindlich als "ohne Widersprüchlichkeit" übersetzt ist ${ }^{65}$, auch auf den Satz [6] beziehen. Dann ist es offensichtlich nicht möglich, "ohne Widersprüchlichkeit" (14) und (15) zu behaupten; aber diese Feststellung gilt eben auch nur dann, wenn wenigstens eine der oben genannten Voraussetzungen (a), (b), (c) explizit angegeben wird. Der Satz [6] bei Lyons müßte daher korrekt z.B. bei der Voraussetzung (b) so heißen:

Man sagt, daß ein Behauptungssatz $S_{1}$ einen anderen Behauptungssatz $S_{2}$ impliziert (wobei $S_{1}, S_{2}$ hier und nachfolgend Variablen für Namen von Behauptungssätzen aus e i n e $r$ natürlichen Sprache L sind), wenn Sprecher von $L$ darin übereinstimmen, daß es nicht möglich ist, wenn $S_{1}$ und $S_{2}$ auf ein und dasselbe Referenzobjekt in der gleichen Situation bezogen werden, $S_{1}$ explizit zu behaupten und $S_{2}$ ohne inhaltlichen Widerspruch zu $S_{1}$ explizit zu verneinen. Oder: ... daß es nicht möglich ist, dasjenige, was mit $S_{1}$ explizit behauptet wird, und zugleich dasjenige, was mit $S_{2}$ explizit verneint wird, bei derselben Interpretation (Welt, Situation) als Tatsache zu erweisen. Oder:... daß es nicht möglich ist, daß die Proposition von $S_{1}$ und die von $S_{2}$ zusammen wahr sind. Welche von die- 
sen drei Möglichkeiten gewählt wird, hängt von den Details des "framework" ab, innerhalb dessen diese Explikationen zu denken sind. Unter den Voraussetzungen (a) oder (c) kann ein entsprechender Satz gemäß diesen Voraussetzungen formuliert werden.

Nun scheint nach Lyons wenigstens Folgendes festzustehen:

$S_{1}$ impliziert $S_{2}$ besagt das gleiche wie $S_{2}$ folgt analytisch aus $S_{1} .66$ Zunächst müssen wir nun klären, was nach Lyons "analytisch" heißen soll. Lyons schreibt:

"Eine analytische Feststellung ist eine, die 'notwendig' wahr ist; ihre Wahrheit ist festgelegt (1) durch den Sinn ihrer konstituierenden Elemente und (II) durch die syntaktischen Regeln der Sprache. Um ein Standardbeispiel zu nehmen: Der Satz Alle Junggesellen sind unverbeiratet kann als analytisch in dem Sinne betrachtet werden, $\mathrm{da}$ Junggeselle und unverbeiratet derart semantisch miteinander in $\mathrm{Be}$ ziehung gesetzt sind, daß die Wahrheit des Satzes feststeht." 67

Diese Bestimmung ist relativ zum derzeitigen Stand der Diskussion zum Begriff der Analytizität bzw. zum Begriffspaar analytisch vs. syntethisch $z$ war überholt, und zwar u.a. deswegen, weil unklar ist, was das von Lyons bezeichnenderweise in A nführungszeichen gesetzte " 'notwendig' " eigentlich heißen soll. ${ }^{68}$ Es scheint mir aber realistisch zu sein, wenn Lyons davon ausgeht, daß die Lösung derjenigen Fragen, die von einer präzisen Unterscheidung von kontingenter Wahrheit einerseits und notwendiger Wahrheit andererseits abhängen, bei einer semantischen Analyse natürlicher Sprachen nicht unbedingt vorausgesetzt werden müssen. Lyons schreibt daher:

"Was der Linguist benötigt, ist ein pragmatisches Konzept der Analytizität - ein Konzept, welches in der Theorie die in der Sprachgemeinschaft stillschweigend vorausgesetzten Kenntnisse und Annahmen anerkennt und andererseits von einer Wertung innerhalb eines anderen Bezugssystems, von dem man annimmt, daß es absolut oder linguistisch und kulturell neutral ist, absieht." 69

"Notwendig wahr" ist daher hier aufzufassen als wahr relativ zum regelgerechten Gebrauch einer natürlichen Sprache L (in eingeschränkten Kontexten) und damit relativ zu allgemeinen Kenntnissen und Annahmen, die in diesem regelgerechten Sprachgebrauch ausgedrückt werden. Damit ist auch der Ausdruck "without contradiction" nicht notwendigerweise als "ohne logischen Widerspruch" zu verstehen. Vielmehr handelt es sich eher um einen Widerspruch relativ zu einer Anzahl in einer Sprachgesellschaft bezüglich einer Welt anerkannter Wahrheiten, die beim Sprechen über diese Welt vorausgesetzt werden. ${ }^{70}$

Wenn Lyons sagt $S_{1} \supset S_{2}$, dann ist dies offenbar aufzufassen als "Aus $S_{1}$ folgt semantisch analytisch $S_{2}$ ". Es handelt sich also um die Relation des 
Einschlusses (entailment), die so definiert werden kann: $S_{1}$ schließt $S_{2}$ genau dann ein, wenn Sprecher darin übereinstimmen, daß - in ein und derselben Situation - die Wahrheit von $S_{2}$ notwendig aus der Wahrheit von $S_{1}$ und die Falschheit von $S_{1}$ notwendig aus der Falschheit von $S_{2}$ folgt. ${ }^{71}$ Wenn nun Sprecher darin übereinstimmen, daß - wenn man einen Satz $S_{2}$ in der gleichen Situation nicht ohne Widerspruch explizit verneinen kann, dann offenbar deswegen, weil für sie die Wahrheit von $S_{2}$ aus der Wahrheit von $S_{1}$ (und die Falschheit von $S_{1}$ aus der von $S_{2}$ ) folgt und damit $S_{1} S_{2}$ einschließt.

Wenden wir diese Bestimmung auf unsere Sätze (14), (14a) und (15) an, dann engibt sich: (14) つ (14a), d.h.: aus (14) folgt semantisch analytisch (14a), da (15) nicht ohne Widerspruch explizit verneint werden kann; wenn (14) wahr ist, dann auch (14a) und wenn (14a) falsch ist, dann auch (14).

Sprecher des Deutschen werden sich leicht darüber einig sein, daß die gegebene Beurteilung gültig ist: Faschisten, Anarchisten, Jusos, Kommunisten, Konservative, kurz alle, die mit ihrer Sprachkenntnis auch wissen, daß alle Quadrate Vierecke sind, werden hier in ihrem Urteil übereinstimmen. Sie alle verfügen über eine semantische Ähnlichkeitsbeziehung der Wörter Quadrat und Viereck, die sich theoretisch als lexikalische Hyponymie, in der Quadrat zu Viereck steht, rekonstruieren läßt. Für sie alle ist der Satz

\section{(16) Alle Quadrate sind Vierecke}

analytisch.

Die soeben behandelten Beispielsätze scheinen nahezulegen, daß sich über Implikationsbeziehungen von Sätzen relativ leicht Konsens erzielen läßt. Das ist jedoch nicht der Fall, wie folgende Beispielsätze zeigen:

\section{(17) Hans ist kommunistiscb}

\section{(18) Hans ist totalitär}

Hier wird man sich streiten, ob (18) aus (17) semantisch analytisch folgt, da eben manche Sprecher des Deutschen behaupten, daß Kommunisten genau so wie Faschisten totalitär sind, demnach die sog. Totalitarismusthese vertreten, andere Sprecher dies aber gerade bestreiten. ${ }^{72}$

Wenn schon bei der unilateralen Implikation die Übereinstimmung in der Beurteilung nicht zu erzielen ist, dann ist zu erwarten, daß dies auch bei der bilateralen Implikation oder Äquivalenz der Fall ist. Nehmen wir folgende Beispielsätze:

(19) Peter ist ein Polizeispitzel 
Impliziert nun (19) (20) und umgekehrt (20) (19)? Folgt z.B. daraus, daß es wahr ist, daß Peter ein Polizeiinformant ist auch, daß es wahr ist, daß Peter ein Polizeispitzel ist? Offensichtlich hängt das davon ab, wie diejenigen, die darüber urteilen sollen, zu Peter, zur Polizei etc. stehen. Ob also die Wörter Polizeispitzel und Polizeiinformant lexikalisch synonym sind, ob (19) und (20) intensionale Paraphrasen voneinander sind, kann auf diesem Wege keineswegs mit Sicherheit entschieden werden, da man sich bereits über die Äquivalenz von (19) und (20) streiten kann.

Daß der Begriff der Implikation und der der Äquivalenz, angewandt auf Sätze der natürlichen Sprache, solche Diskussionen nicht ausschließen und damit das nicht leisten, was sie relativ zu logischen Sprachen leisten, hängt damit zusammen, daß natürliche Sprachen - im Unterschied zu logischen keine vollständig interpretierten Sprachen sind, sondern allenfalls als hinsichtlich ihrer möglichen Interpretationen beschränkte Sprachen aufzufassen sind..$^{73}$ Oder anders gesagt: Sätze logischer Sprachen sind formal und relativ analytisch ${ }^{74}$, und daher sind Sätze logischer Sprachen aufgrund ihrer logischen Form und relativ zu semantischen Festsetzungen (z.B. Wahrheitswerttabellen, Interpretationen) vollständig analysierbar. Sätze natürlicher Sprache sind allenfalls semantisch analytisch und d.h. nicht relativ zu semantischen Festsetzungen, sondern nur relativ zur Sprachkenntnis und -beherrschung und insbesondere zur Regelbeherrschung von Menschen analysierbar.

Damit kann dieser Exkurs abgebrochen werden. Die Anwendung eines relativ schillernden Implikationsbegriffes zur Definition von Bedeutungsrelationen, in denen Ausdrücke einer natürlichen Sprache zueinander stehen, stellt - wenigstens im Falle der Synonymie - insofern theoretisch keinen nennenswerten Fortschritt dar, als die Beurteilung der Bedeutungsgleichheit von Sätzen lediglich auf die Beurteilung von Implikationsbeziehungen verschoben wird, ohne daß der Beurteiler bei der Beurteilung von Implikationsbeziehungen über sicherere theoretische Kriterien verfügt. ${ }^{75}$

\subsubsection{Die Rolle der Sprachintuition bei der Erstellung lexikalischer Paraphrasen}

Damit ist für das Verständnis von Wörterbucheinträgen, insbesondere für das von lexikalischen Paraphrasen und das der Synonymierelation klar: Welche Quasi-Experimente mit Sprache oder Sprachtests wir auch immer machen: eine im strengen Sinne theoretische oder gar formale Entscheidung über die Bedeutungsgleichheit zweier oder mehrerer Wörter oder sonstiger sprachlicher Ausdrücke oder überhaupt über das Vorliegen von 
Bedeutungsrelationen liefern sie nicht, da sie nicht automatisch, d.h. subjektunabhängig funktionieren. Damit sind wir auf die Sprachintuition, auf die intuitiven Erkenntnisse von Sprechern verwiesen. Was Searle über deren Rolle in der linguistic philosophy sagt, gilt gleichermaßen für die Lexikographie:

\begin{abstract}
"Aber alle sprachphilosophischen Arbeiten, die ich kenne, selbst die Arbeiten der am extremsten behaviouristischen und empiristischen Autoren, vertrauen ebenfalls auf die intuitiven Erkenntnisse des Sprechers. Etwas anderes ist auch kaum vorstellbar. Denn die Forderung, meine intuitive Einsicht zu rechtfertigen, daß 'Junggeselle' unverheirateter Mann bedeutet, müßte konsequenterweise auch die Forderung einschließen, meine intuitive Einsicht zu rechtfertigen, daß Junggeselle in dem einen Falle dasselbe bedeutet wie in einem anderen. Solche intuitiven Einsichten lassen sich in der Tat rechtfertigen, aber nur, indem auf andere intuitive Einsichten zurückgegriffen wird."76
\end{abstract}

Die Beurteilung von semantischen Ähnlichkeitsbeziehungen, die Entscheidung zwischen verschiedenen Beurteilungen, die Rekonstruktion von Bedeutungsbeziehungen als Bedeutungsrelationen innerhalb eines theoretischen Konzepts ist - unter Kontrolle am belegten Sprachgebrauch abhängig von der Sprachintuition, Sprach- und damit Weltkenntnis sowie der Walt auffassung der Lexikographen. Das kodifizierte Ergebnis einer solchen Entscheidung ist der Wörterbucheintrag, insbesondere derjenige Teil, den wir lexikalische Paraphrase nennen und als verkürztes, behauptendes Urteil über Bedeutungsbeziehungen aufgefaßt haben.

Geurteilt wird über den regelgerechten Sprachgebrauch (innerhalb bestimmter Kon- und Kotexte) in einer vorausgesetzten, inhomogenen Sprachgesellschaft.

Wörterbücher können die Welt- und Sprachkenntnis eines Wörterbuchbenutzers erweitern. Sie teilen Erfahrungen u.a. über sprachliche Bedeutungsbeziehungen sprachlich mit; d.h. : sie können den bereits spracherfahrenen Wörterbuchbenutzer in ihm persönlich neue, aber von vielen anderen bereits gekannte sprachliche Erfahrungszusammenhänge einspielen, insbesondere in konventionalisierte und sprachnormgerechte Gebrauchsweisen der Wörter. Man kann diesen Sachverhalt - bei aller Vorsicht - vielleicht auch so ausdrücken: Da Wörterbucheinträge den Benutzer nur in bereits prinzipiell bekannte sprachliche Erfahrungszusammenhänge einspielen können, sind zwar die lexikalischen Paraphrasen in Wörterbucheinträgen nicht als verkürzte Urteile a posteriori zu qualifizieren, sie können aber für den einzelnen Wörterbuchbenutzer den gleichen Effekt haben wie solche, d.h. die sprachliche Erfahrung von Einzelnen durch eine umfassendere sprachliche Erfahrung erweitern. Die Schreibakte der Lexikographen können auf jeden Fall als sprachliche Akte aufgefaßt werden, 
die u.a. unter der Intention ausgeführt werden, die Spracherfahrung einzelner Wörterbuchbenutzer zu erweitern.

\subsubsection{Zur Wahrheit lexikalischer Paraphrasen}

Damit sind wir wieder bei der Frage der Wahrheit, die bereits in Abschnitt 2.2. angesprochen wurde. Denn eine "wirkliche" Erweiterung der Spracherfahrung, d.h. eine, die den Regeln entspricht, ist nur dann möglich, wenn die Wörterbucheinträge "stimmen", d.h., wenn mit 'Veterinär' Tierarzt etwas behauptet ist, das der Fall ist, oder wenn (10) wahr ist!

Damit taucht nun die Frage auf: Behaupten die Lexikographen, daß die lexikalische Paraphrase 'Veterinär' Tierarzt für alle Fälle "stimmt"? Oder behaupten sie sogar etwa, daß der Wörterbuchbenutzer den Sprachgebrauch anhand des Wörterbuches z.B. als "richtig" oder "falsch" beurteilen soll? Oder anders ausgedrückt: Können Wörterbucheinträge, insbesondere die der Form 'Lemma' Wort als Bedeutungsvorschrift aufgefaßt werden, die eventuell beim Ubergang zu einer formalen Sprache als Bedeutungspostulat (im Sinne R. Carnaps) zu rekonstruieren wäre? ${ }^{77}$ Ich möchte diese letzte Frage verneinen; denn Carnaps Begriffsbildung bezieht sich expressis verbis auf logische Sprachen und kann nicht, ohne daß Aporien entstehen auf natürliche übertragen werden. ${ }^{78}$

Beim Umgang mit Konstruktsprachen sind genaue Vorschriften über die Bedeutungsbeziehungen von konstruktsprachlichen Ausdrücken sicherlich unbedingt erforderlich. Dazu ein elementares Beispiel.

\section{BEISPIEL Nr. 5}

Nehmen wir an: wir verfügen über eine künstliche Sprache, die als Ausdrücke für die Größerbeziehung, in der natürliche Zahlen zueinander stehen können, folgende zwei Ausdrücke hat: $a>\beta$ und G $(a, \beta)$. Dann muß - um die formale und relative Analytizität zu gewährleisten - die Bedeutungsbeziehung zwischen diesen beiden Ausdrücken in einer $\mathrm{Be}$ deutungsvorschrift explizit formuliert werden. Man setzt dann folgendes fest : $a>\beta \Leftrightarrow \mathrm{G}(a, \beta)$, wobei der Doppelpfeil " $\Leftrightarrow$ " als "ist intensional isomorph" (im Sinne Carnaps) zu lesen ist. ${ }^{79}$

Eine solche Bedeutungsvorschrift hat nun den Zweck, als verbindliche Berufsinstanz zu gelten: d.h. beim Gebrauch und der Analyse dieser Kunstsprache muß man sich stets auf diese Bedeutungsvorschrift berufen. Sie verneint strikt für alle konstruktsprachlichen Vorkommen einen Bedeutungsunterschied der beiden Ausdrücke.

Wörterbucheinträge in Wörterbüchern, die natürliche Sprachen kodifizieren, lassen sich dagegen nicht als verbindliche Berufungsinstanzen auf- 
fassen, relativ zu denen Benutzer stets semantisch korrekt und in allen Fällen stets gleich Texte analysieren und verstehen können. Ein Wörterbucheintrag der Form 'Lemma' Wort kann daher auch nicht so verstanden werden, daß er von vornherein strikt jeden möglichen Bedeutungsunterschied in Texten verneint. Die Aufgabe des Lexikographen bzw. seine Schreibakte können auch nicht so aufgefaßt werden: es wird mit ihnen ein System von Bedeutungsbeschränkungen für alle Fälle festgesetzt. Daher lassen sich Wörterbucheinträge auch nicht als Bedeutungspostulate rekonstruieren. 80

Aus diesen Uberlegungen ergeben sich nun wenigstens die folgenden drei Feststellungen.

(1) Die "Wahrheit der Wörterbucheinträge" ist nicht für jeden, sondern nur für bestimmte Sprachgebräuche gegeben.

(2) Der Synonymiebegriff muß kon- und kotextspezifisch sein, d.h. die Synonymierelation ist mehr als zweistellig.

(3) Eine Auffassung der Synonymie als Bedeutungsgleichheit erscheint - im Rahmen der Lexikographie - als problematisch.

Damit ist die Richtung der weiteren Argumentation angedeutet.

\subsubsection{Dritte Leseart: Synonymie als Gleichheit von Gebrauchsregeln}

Wenn Lexikographen in ihren Wörterbucheinträgen über den regelgerechten Sprach g e b r a u c h urteilen, dann muß jetzt gefragt werden, was es eigentlich heißen soll, daß das Wort Tierarzt dem Wörterbuchbenutzer etwas über den Gebrauch ${ }^{81}$ des als Lemma angesetzten Wortes Veterinär sagt.

Gehen wir einmal im Anschluß an Wittgenstein davon aus, daß die Bedeutung eines sprachlichen Ausdruckes die Regeln seines Gebrauchs in derjenigen Sprache sind, zu der dieser Ausdruck gehört. ${ }^{82}$ Dann ergibt sich für unseren Wörterbucheintrag zunächst einmal folgende, allerdings noch sehr allgemeine dritte Leseart: 83

Das Wort Veterinär folgt den gleichen Gebrauchsregeln wie das Wort Tierarzt.

Diese Leseart soll sich von der vorhergehenden nur dadurch unterscheiden, daß explizit auf eine bestimmte Bedeutungsauffassung bezug genommen wird; es wird aber weiterhin eine zweistellige Relation ausgedrückt. Sie besagt - aufgefaßt als lexikographische Behauptung - daß Sprecher des Deutschen uneingeschränkt beim regelgerechten Gebrauch des Wortes Tierarzt den gleichen sprachlichen Regeln folgen wie beim Gebrauch von 
Veterinär. Ein Verständnis des so aufgefaßten Wörterbucheintrages hängt demnach auch davon $a b$, ob überhaupt und wenn, wie wir verstehen, was der Begriff "einer Regel folgen" besagt. ${ }^{84}$

\subsubsection{Vierte Leseart: Synonymie als Gleichheit von Bezugsregeln relativ zu Referenzbereichen}

Fragen wir nun kurz, ob die Gleichheit der Gebrauchsregeln etwas mit der Gleichheit der Extensionen der Wörter Veterinär und Tierarzt zu tun hat. Der Begriff der Extension spielt u.a. im Zusammenhang der semantischen Interpretation von logischen Sprachen eine wichtige Rolle und ist hier stets dann relativ genau definierbar, wenn man sich über ontologische Fragen geeinigt und insbesondere über den Begriff der Identität einen Konsens hergestellt hat. ${ }^{85}$ So kann z.B. innerhalb eines festgesetzten "universe of discourse", einem Bereich von stets als identisch identifizierbaren Entitäten, der die Bedeutungen (im Sinne G. Freges) liefert, die Extension einer Prädikatskonstanten mittels einer Interpretationsfunktion eindeutig festgesetzt werden. Der semantisch korrekte Gebrauch dieser Prädikatskonstanten ist dann eine Funktion ihrer festgesetzten Extension. Zwei verschiedene Prädikatskonstanten derselben formalen Sprache werden dann semantisch gleich gebraucht, wenn ihre Extensionen identisch sind. ${ }^{86}$ In natürlichen Sprachen ist aber manches totaliter aliter. Mit natürlichen Sprachen können Menschen prinzipiell über alles reden. Eingegrenzte Bereiche anzugeben, über die geredet werden soll oder darf, hieße, eben eine natürliche auf eine bereichsspezifische Sprache zu reduzieren; solche semantischen Reduktionen können z.B. zu Fachsprachen führen. Mit natürlichen Sprachen kann man in einem Zug über ganz verschiedene Bereiche reden: eben noch über die wirkliche Welt, sogleich über Traumwelten, dann über Glaubenswelten, fiktive Welten etc. Dies heißt zugleich, daß die Extension z.B. eines Prädikats der natürlichen Sprache nicht in der gleichen Weise konstant ist; eine Konstanz ist allenfalls ko- und kontextspezif isch feststellbar, d.h. natürlichsprachliche Prädikate können als variable Konstante ${ }^{87}$ aufgefaßt werden. Der semantisch korrekte Gebrauch eines natürlichsprachlichen Prädikats ist daher keine Funktion nur einer festgesetzten Extension.

Zwei Beispiele sollen nun illustrieren,was damit gemeint ist.

BEISPIEL Nr. 6

Der Graf von Monte Christo sagt: "Icb habe vergangene Nacht von einem Land geträumt, in dem Veterinäre keine Tierärzte sind."

Relativ zur (oder: in der) Traumwelt des Grafen sind die Extensionen von 
Veterinär und Tierarzt nicht gleich sondern disjunkt; deshalb ist z.B. die Existenzaussage Es gibt einen Veterinär, der kein Tierarzt ist in der Traumwelt des Grafen gültig, während die gleiche Existenzaussage hinsichtlich der realen Welt, in der wir leben, wahrscheinlich kaum a ls gültig erwiesen werden kann. In einer sprachlichen Wiedergabe seines Traumes z.B. kann dann der Graf mit den Worten Veterinär und Tierarzt ganz anders ref erieren. Man wird in einem solchen Falle aber einerseits nicht argumentieren, daß der Graf die beiden Wörter semantisch nicht regelgerecht gebraucht, wenn bekannt ist, daß er über einen Traum spricht; andererseits aber wird man nicht sagen wollen, daß der Wörterbucheintrag 'Veterinär' Tierarzt semantisch inkorrekt sei.

Die kurze Betrachtung des Beispiels Nr. 6 gibt uns demnach einen weiteren Hinweis darauf, daß eine lexikalische Paraphrase in einem Wörterbucheintrag $\mathrm{r}$ e la $\mathrm{t}$ i v $\mathrm{z}$ u ... geschrieben wird und demnach kein lexikographisches Urteil über jeden beliebigen Gebrauch des Lemmas darstellt.

BEISPIEL Nr. 7

Man kann gute Gründe dafür angeben, daß die Wörter Pisse, Urin und Harn die gleiche Extension haben. Was wird man aber zu folgendem Sprachgebrauch sagen?

Der Chefarzt eines Krankenhauses ruft seiner Laborantin in der Gegenwart seiner Privatpatientin zu: "Ist die Pisse der gnadigen Frau scbon untersicbt?"

Offensichtlich hat der Arzt die Gebrauchsregeln des Wortes Urin auf das Wort Pisse angewendet. Man sollte ihm den "Wahrig" empfehlen, denn der warnt seine Benutzer vor solchem Gebrauch, indem er hinter das Lemma 'Pisse' den zusätzlichen Gebrauchshinweis [ vulgär] setzt. ${ }^{88}$

Dieses Beispiel zeigt nun, daß - auch ohne daß Traumwelten bemüht werden müssen - die Gebrauchsregeln zwar in einem Zusammenhang mit der Extension von sprachlichen Ausdrücken gesehen werden müssen, nicht aber als Funktion nur der Extension aufgefaßt werden können.

Wir lassen den Begriff der Extension nun beiseite und sprechen stattdessen von Referenzbereichen, Referenzobjekten, Referenz- und Prädikationsregeln und fassen letztere als zwei untereinander disjunkte Subklassen der semantischen Gebrauchsregeln auf. An zwei Beispielsätzen sei erläutert, was mit der Unterscheidung von Referenz- und Prädikationsregeln gemeint ist. ${ }^{89}$

(21) Der Veterinär bustet

(22) Herr Müller ist ein Veterinär

Wird (21) geäußert, ist Veterinär referierend gebraucht, d.h. es wird identifizierend auf ein Referenzobjekt verwiesen. Wird (22) geäußert, ist Vete- 
rinär prädizierend gebraucht, d.h. intensional ausgedrückt: Herrn Müller wird die Eigenschaft zugesprochen, ein Veterinär zu sein; oder extensional formuliert: Herr Müller wird als Veterinär klassifiziert. Um nachfolgend einfacher reden zu können, benutze ich für Referenz- und Prädikationsregeln als übergeordneten Ausdruck Bezugsregeln.

Nach diesen $\mathrm{Z}$ wischenüberlegungen können wir nun die dritte Leseart unseres Wörterbucheintrages derart zu einer vierten umformulieren, daß eine dreistellige Relation ausgedrückt wird, so daß sie lautet:

Das Wort Veterinär folgt relativ zu dem Referenzbereich "Realität, in der wir leben", den gleichen Bezugsregeln wie das Wort Tierarzt.

Diese Behauptung über den Gebrauch unserer beiden Wörter kann an zahlreichen Beispielen überprüft werden. Hier nur das folgende:

BEISPIEL Nr. 8

Paul hat einen Furunkel am Hals, wird von seinem Hausarzt, also einem Humanmediziner, behandelt, und dieser tut ihm dabei schrecklich weh. Paul ruft: "Au, Sie sind ja der reinste Tierarzt!" (oder auch: "Au, Sie Tierarzt!").

Paul hätte aber auch äußern können: " $A u$, Sie sind ja der reinste Veterinär!" (oder auch: "Au, Sie Veterinär"). Er hätte dann das gleiche gemeint.

Beispiele, in denen Sprecher die beiden Wörter derart verwenden, sind demnach - so scheint es - nicht in der Lage, unsere Behauptung zu falsifizieren.

\subsubsection{Unterscheidung von usuellen und nicht-usuellen Kotexten}

Anhand des Beispiels Nr. 8 läßt sich eine Unterscheidung einführen, von der ich glaube, daß sie für Lexikographen sehr nützlich ist, und die wir später noch benötigen. Wir können zwischen usuellen und nicht-usuellen Kotexten unterscheiden, indem wir die Unterscheidung von sagen und meinen im Sinne von H.P. Grice aufgreifen, ohne auf Einzelheiten einzugehen. ${ }^{90}$

Gehen wir davon aus, daß ein sprachlicher Ausdruck etwas bedeutet und ein Sprecher S dieses Ausdruck A verwendet, um jemanden etwas zu $s a-$ gen, und gehen wir weiter davon aus, daß S, indem er A sagt, etwas meint, dann ist das, was $\mathbf{S}$ sagt, nicht notwendig identisch mit dem, was er meint. Nicht-usuelle Kotexte ${ }^{91}$ sind nun solche, mit denen jemand etwas anderes sagt als er meint. Das Beispiel Nr. 8 ist in diesem Sinne ein nicht-usueller Kotext, denn Paul sagt hier etwas anderes als er meint. Er sagt von seinem Hausarzt zwar, er sei ein Tierarzt, aber er meint offensichtlich nicht, daß 
sein Hausarzt zur Klasse der Tierärzte zu rechnen ist, vielmehr meint er etwa: "Sie sind aber ganz schön grob". Oder anders ausgedrückt: Paul implikatiert (als Übers. des Grice'schen implicate $\neq$ imply) ${ }^{92}$ die Proposition, daß der Mediziner ganz schön grob ist, weil er sie ausdrückt, ohne sie ("wörtlich") zu sagen. - Das Beispiel Nr. 8 zeigt überdies, daß es nichtusuelle Kotexte gibt, in denen "Synonyme" wie Veterinär und Tierarzt austauschbar sind, ohne daß sich die Bedeutung ändert.

Usuelle Kotexte dagegen sind solche, mit denen jemand sagt, was er meint. Dazu folgendes Beispiel

\section{BEISPIEL Nr. 9}

Nehmen wir an: Herr Müller ist Tierarzt und hat Herrn Schmitt angerufen. Dann kann Herr Schmitt zu seiner Frau sagen: "Der Tierarzt Müller hat eben angerufen". Dies ist ein usueller Kotext. Herr Schmitt hat gesagt, was er gemeint hat. Er hätte aber dasselbe gemeint, wenn er gesagt hätte: "Der Veterinär Müller bat eben angerufen. "Auch hier sind demnach Tierarzt und Veterinär austauschbar.

Aus diesen beiden Beispielen scheint nun zu folgen, daß wir unsere letzte Leseart für den Wörterbucheintrag nicht durch eine Kotextangabe spezifizieren müssen. Wir kommen jedoch auf diesen Punkt sogleich zurück.

\subsubsection{Fünfte Lesart: Synonymie als Gleichheit von Bezugsregeln} relativ zu Referenzbereichen und in usuellen Kotexten

Wir fragen daher nun: Sind Wörterbucheinträge der Form 'Lemma' Wort - auch wenn das von Lexikographen nicht explizit gesagt ist - nicht doch nur relativ zu bestimmten Kotexten behauptet? Um dieser Frage nachzugehen, wenden wir uns nun den folgenden zwei Beispielen zu.

BEISPIEL Nr. 10

Peter wird gefragt: "Wie war's denn im Krankenbaus?" Er antwortet: "Eigentlich recht erfreulich; das Essen und aucb die Pflege waren prima, aber: Ein Krankenbaus ist eben ein Krankenbaus."

Hätte Peter auch gleichbedeutend antworten können:

"Ein Krankenhaus ist eben ein Hospital"?

Ich habe hier absichtlich eine Frage formuliert, weil ich mir nicht so sicher bin, ob die beiden (geäußerten) Sätze als bedeutungsgleich zu beurteilen sind oder nicht. Ich neige intuitiv dazu, dies eher zu verneinen und kann dafür folgende Gründe angeben: Es geht offensichtlich Peter nicht darum, die Identität eines Krankenhauses mit sich selbst zu behaupten. Denn diese 
Identität war ja im vorliegenden Kon- und Kotext gar nicht fraglich. Die Frage war vielmehr: "Wie war's denn im Krankenhaus?" Es führt hier wohl auch nicht weiter, wenn wir annehmen, daß Peter einen Satz äußern wollte, der aus logischen Gründen gültig ist, auch wenn er es ist. Wir müssen daher den Schluß ziehen, daß Peter etwas anders gesagt hat als er gemeint hat, es sich also bei dem fraglichen Satz um einen nicht-usuellen Kotext handelt, in dem - im Unterschied zum Beispiel Nr. 8 - die "Synonyme" Krankenbaus und Hospital nicht austauschbar sind.

Was aber hat nun Peter gemeint? Wahrscheinlich etwa Folgendes: Relativ zu möglichen Verhältnissen in Krankenhäusern war sein Krankenhausaufenthalt eigentlich recht erfreulich, weil nämlich z.B. das Essen und die Pflege gut waren. Relativ zu möglichen Verhältnissen außerhalb von Krankenhäusern war es aber dann doch nicht so erfreulich. Denn: ein Krankenhaus ist eben ein Krankenhaus.

Eine solche intuitive Analyse des Gemeinten, die sich systematisieren ließe, sagt demnach, daß Peter seinem Gesprächspartner zu einem Vergleich auf der Basis von dessen Kenntnissen über die Verhältnisse in Krankenhäusern veranlassen will, und zwar indem er selbst einen unausgesprochenen und daher impliziten Vergleich macht.

Hätte er aber dasselbe kommunikativ erreichen und meinen können, wenn er gesagt hätte: "Ein Krankenbaus ist eben ein Hospital"? I ch glaube nicht! ${ }^{93}$ Denn er hätte mit diesem Satz wohl die Aufmerksamkeit seines Gesprächspartners mehr auf die Frage gelenkt, welcher Unterschied denn eigentlich zwischen Krankenhäusern und Hospitalen besteht, also genau auf die Frage der Identität, demnach auf etwas, was gar nicht fraglich war und was er wohl daher nicht gemeint hat.

Folgendes Beispiel hat wieder direkten Bezug auf unseren Wörterbucheintrag.

BEISPIEL Nr. 11

Tierarzt Schreiber verabschiedet sich von Marianne mit den Worten: " $M a$ chen Sie's gut! Und übrigens: gegen Ibre Grippe bilft nur so eine ricbtige Pferdekur!" Marianne antwortet daraufhin lachend: "Danke für den Tip. Ein Tierarzt bleibt eben ein Tierarzt!"

Wir können hier entsprechend fragen: Hätte Marianne auch gleichbedeutend antworten können: "Ein Tierarzt bleibt eben ein Veterinär" oder: "Ein Veterinär bleibt eben ein Tierarzt"?

Der Austausch der beiden Wörter ergibt auch in diesem Beispiel - nach meiner intuitiven Beurteilung - bedeutungsverschiedene Kotexte. Zur 
Interpretation des Beispiels nur eine Bemerkung. Auffallend ist, daß die beiden (möglichen) Antworten, in denen das durchsichtige Wort Tierarzt prädizierend gebraucht wird, intuitiv eher als gleichbedeutend beurteilt werden. Wahrscheinlich hängt dies damit zusammen, daß mit oder in der Durchsichtigkeit des Wortes Tierarzt wenigstens ein Teil desjenigen, was Marianne gemeint aber nicht gesagt hat, zum Ausdruck kommt, nämlich, daß Tierarzt Schreiber - sei sein Tip nun ironisch, ernst oder sonst wie aufzufassen - sich mit seiner Äußerung eben als Arzt für Tiere (und nicht einer für Menschen) erweist. ${ }^{94}$

Es scheint mir nun möglich, aus diesen Beispielen - auch wenn ihre Analyse keineswegs hinreichend ist - zu folgern, daß es zumindest sicherer ist, die vierte Lesart des Wörterbucheintrages doch um eine Kotextspezifik zu ergänzen, so daß sie eine vierstellige Relation zum Ausdruck bringt und lautet:

Das Wort Veterinär folgt relativ zum Referenzbereich "Realität, in der wir leben", wenn es in usuellen Kotexten steht, den gleichen Bezugsregeln wie das Wort Tierarzt.

Für Lexikographen muß übrigens gelten, daß sie die lexikalischen Paraphrasen der Lemmata in einsprachigen Wörterbüchern nur hinsichtlich usueller Kotexte formulieren. Alles andere wäre eine Úberforderung möglicher Praxis. ${ }^{95}$ Das zeigt deutlich folgendes Beispiel.

BEISPIEL Nr. 12

Matthias sitzt mit seinem Vater bei den Mathematikaufgaben. Matthias ist unkonzentriert, kaut auf seinem Bleistift herum und der Vater ist nervös, weil der Sohn nun schon zum dritten Mal die Element- mit der Teilmengenbeziehung verwechselt. Er fährt Matthias an: "Herrgott, nun nimm doch endlicb diesen Kaugummi aus dem Mund und paß besser auf!" 96

\subsubsection{Synonymie und Bedeutungsgleichheit}

Bisher haben wir den Relationsausdruck ist synonym mit verstanden als "ist bedeutungsgleich mit". Diese Interpretation haben wir bisher unbefragt gelassen, wollen daher jetzt fragen, ob sie überhaupt gerechtfertigt ist. Wir hatten ja u.a. schon im letzten Abschnitt bemerkt, daß eine Austauschbarkeit, ohne die Bedeutung zu ändern, in gewissen nicht-usuellen Kotexten nicht möglich erscheint; d.h.: es gibt Fälle, in denen die Wörter Veterinär und Tierarzt unserem starken Gleichheitskriterium nicht genügen. Die Frage ist nun, ob es weitere überzeugende und generalisierbare Fälle gibt. Betrachten wir daraufhin folgende Sätze:

Tierärzte sind Tierärzte 


\section{(25) Tierärzte sind Veterinäre}

Satz (23) hat mit dem fraglichen Satz im Beispiel Nr. 11 gemeinsam, daß Tierarzt sowohl referierend als auch prädizierend gebraucht wird. Die Ersetzung führt zu den Sätzen (24) und (25), die eventuell untereinander, nicht aber jeder für sich mit (23) bedeutungsgleich sind. Denn (23) ist als Identitätsaussage aus logischen Gründen gültig, d.h. tautologisch oder apriori wahr und vermittelt niemanden eine neue (empirische) Erkenntnis oder Erfahrung. (24) und (25) dagegen sind aus (sprach-)empirischen Gründen gültig, d.h. können als Identitätsaussagen erst erkannt werden, wenn man etwas über die Bedeutungsbeziehung von Veterinär zu Tierarzt weiß, können außerdem einzelnen eine für diese neue Erkenntnis vermitteln und daher wie synthetische Urteile a posteriori wirken.97

Bei der Beurteilung der Beispiele Nr. 10 und 11 waren wir nicht ganz sicher; als Falsifikation der Gleichheitsauffassung wollen wir sie daher nicht ohne weiteres gelten lassen. Für die Sätze (23), (24) und (25) kann nun aber argumentiert werden, daß das Gleichheitskriterium modifiziert werden muß, und zwar wie folgt: Kommt in einem Kotext ein Wort mehr als einmal vor, dann ist es in allen seinen Vorkommen zu ersetzen. Mit dieser Zusatzbedingung erhält man das folgende Satzpaar :

(23) Tierärzte sind Tierärzte

(26) Veterinäre sind Veterinäre

Nun sind (23) und (26) bedeutungsgleich. Lassen wir diese Zusatzbedingung auch für die Substitution in den fraglichen Sätzen unserer Beispiele Nr. 10 und $11 \mathrm{zu}$, entstehen auch hier nur jeweils bedeutungsgleiche Sätze. Unser Vorgehen zeigt im übrigen nun deutlich, daß die Auffassung, welche Ausdrücke synonym sind oder nicht - wenn Austauschbarkeit als Rahmenkriterium herangezogen wird - von den einzelnen Austauschbedingungen abhängt. Werden diese geändert, ändert sich auch die Extension des Begriffes der (substitutiven) Synonymie. ${ }^{98}$ So ergibt sich hier erst nach der Einführung der Zusatzbedingung deutlich, daß Veterinär und Tierarzt als bedeutungsgleich aufzufassen sind.

Wir können aber weitere Beispiele finden, die zeigen, daß die Auffassung der Synonymität als Bedeutungsgleichheit problematisch ist, z.B. folgende Sätze:

Tie rarz $t$ beginnt mit dem Bucbstaben $T$

$V$ e t e rinär beginnt mit dem Bucbstaben $T$ 
Offensichtlich sind (27) und (28) nicht bedeutungsgleich. Gegen diese Beispielsätze, in denen sowohl Tierarzt als auch Veterinär weder referierend noch prädizierend gebraucht werden, wird man auf der Basis der Unterscheidung zwischen dem Gebrauch (use) und der Erwähnung (mention) eines sprachlichen Ausdruckes oder unter Hinweis auf die Begriffe Objekt- vs. Metasprache opponieren. Es scheint mir jedoch keine stichhaltigen Argumente auf der Basis dieser Unterscheidungen gegen die Sätze (27) und (28) als Beispiele gegen die Auffassung der Synonymität als Bedeutungsgleichheit zu geben.

Wollten wir nämlich z.B. unser Gleichheitskriterium - gerade schon ein$\mathrm{mal}$ in Analogie zu einer Variablenersetzungsvorschrift in formalen Sprachen verändert - jetzt auch noch um die weitere Bedingung verschärfen, daß Kotexte wie (27) und (28), in denen also die fraglichen Wörter $V e$ terinär und Tierarzt erwähnt werden, auszuschließen sind, dann hätten wir allerdings ein Gleich heitskriterium konstituiert, das von vornherein natürlichen Sprachen und ihrer Verwendung in alltäglichen Kommunikationssituationen nicht angemessen wäre. Denn diese sind semantisch geschlossen und besitzen die Eigenschaft der Selbstreflexivität ${ }^{99}$, die soweit ausgeprägt ist, daß wir keineswegs nur - wie in (27) und (28) - mit den eigens dafür vorgesehenen Ausdrücken wie beispielsweise Sprache, Wort, Satz und Bucbstabe auf sie bezug nehmen können, wie folgendes Beispiel zeigt:

\section{BEISPIEL Nr. 13}

Thomas kommt mit Vaters Wagen aus der Werkstatt. Es ergibt sich folgender Dialog:

Thomas: "Du, auf der Rechnung stebt: '4 Reifen entspeikt - 76 DM"." Vater: "Ja, sauteuer!"

Thomas: "Dabei schreiben die 'entspeikt' mit 'ei'."

Vater: "Na und?"

Thomas: "Was beißt bier 'Na und? '. Das ist docb falsch!"

Vater: "Wieso eigentlich?"

Thomas: "Ja, weil das Englisch ist!"

Vater: "Hast du denn nicht verstanden, was gemeint ist?"

Thomas: "Dumme Frage, natürlich!"

Vater: "Ja, dann ist doch das falsche 'ei" nicht so wichtig."

Thomas: "Das bab'ich doch gar nicht gemeint"

Vater: "Ja, was denn sonst?"

Thomas: "Das ist docb klar. Teure Rechnungen können die macben, aber richtig schreiben können sie nicht. Typisch!" 
Vater: "Acb so, jetzt verstebe icb. Für dicb ist das 'ei' ein Vergeben, so 'ne Art Wertmaßstab für den Meister."

In alltäglichen Dialogen erwähnen wir ständig sprachliche Ausdrücke unserer Sprache. Es scheint mir daher nicht angemessen zu sein zu argumentieren, die Dialogpartner wechselten, wenn sie Ausdrücke erwähnen, in eine andere Sprache oder auf eine andere Sprachstufe, etwa die einer Metasprache über. Wir müssen daher Kotexte wie (27) und (28) zulassen. Denn es wäre eine nicht angemessene Orientierung an den Bedingungen formaler Sprachen, Kotexte mit der Erwähnung von sprachlichen Ausdrücken dann nicht zuzulassen, wenn es darum geht, ein semantisches Gleichheitskriterium für verwendete Ausdrücke aus natürlichen Sprachen zu konstituieren.

Aus diesen Uberlegungen ergibt sich: Beispiele wie (27) und (28) sind zwar nicht geeignet, unsere fünfte Lesart erneut zu verändern, da in ihnen sowohl Veterinär als auch Tierarzt weder referierend noch prädizierend gebraucht werden; sie legen aber doch die Folgerung nahe, ein Verständnis wenigstens des zweistelligen Relationsausdruckes ist synonym mit als "ist bedeutungsgleich mit" abzulehnen.

2.3.3. Sechste Lesart: Synonymie als Ähnlichkeit von Gebrauchsregeln bei Gleichheit von Bezugsregeln...

Unsere fünfte Lesart für Wörterbucheinträge der Form 'Lemma' Wort drückt durch die Berücksichtigung einer Kotextspezifik und eines, auf einen bestimmten Referenzbereich spezifierten Sachbezuges eine vierstellige Relation aus. Die Gleichheit der Bezugsregeln ist damit nicht auf alle, sondern auf bestimmte Verwendungen bzw. bestimmte Verwendungsmöglichkeiten hin ausgesagt. Das bedeutet: es handelt sich um eine Auffassung von beschränkter Bedeutungsgleichheit. In einer Behauptung wie Veterinär ist synonym mit Tierarzt mit zweistelligem Prädikat kann dieses - in unserem Argumentationsrahmen - nur als "ist bedeutungsähnlich mit" aufgefaßt werden. Die Beschränkung der Gleichheit führt zur Auffassung der Ähnlichkeit und diese - da ein Begriff von Ähnlichkeit nur definiert werden kann, wenn im Definiens der Begriff der Gleichheit erneut auftaucht - zur erneuten Behauptung einer Gleichheit, und zwar der von Bezugsregeln hinsichtlich usueller Kotexte und relativ zum Referenzbereich "Realität, in der wir leben".

Die Frage ist nun, ob die damit ausgedrückte Beschränkung der absoluten Gleichheit hinreichend ist, oder anders ausgedrückt, ob in der Behauptung Veterinär ist synonym mit Tierarzt in usuellen Kotexten und relativ zum Referenzbereicb "Realität, in der wir leben" ist synonym mit als "ist be- 
deutungsgleich mit" verstanden werden kann. Diese Frage ist zu verneinen. Denn in unserem Argumentationsrahmen hieße das, daß die Bedeutungsgleichheit zweier Ausdrücke mit der Gleichheit ihrer Bezugsregeln identifiziert werden müßte. Daraus ergäbe sich dann, daß die Bedeutung eines sprachlichen Ausdruckes seine Bezugsregeln in derjenigen Sprache wären, zu der dieser Ausdruck gehört. Nun hatten wir aber die Bedeutung eines sprachlichen Ausdruckes als seine Gebrauchsregeln aufgefaßt und die Bezugsregeln als eine Subklasse der Gebrauchsregeln. Daraus entstehen nun eine Reihe von Fragen, z.B. folgende: Sind hinsichtlich usueller Kotexte und relativ zum Referenzbereich "Realität, in der wir leben" alle Gebrauchsregeln von Veterinär und Tierarzt gleich? Folgen die beiden Wörter stets den gleichen stilistischen Regeln? Werden sie von allen Berufsgruppen und in allen sozialen Schichten gleich gebraucht?

Diese Fragen können verneint werden, weil es zahlreiche stil-, sozial, areal und wertungsbedingte Unterschiede im Gebrauch von Veterinär und Tierarzt gibt, auf die hier nicht im einzelnen eingegangen werden kann. 100 Das bedeutet: es kann auch in usuellen Kotexten und relativ zum Referenzbereich "Realität, in der wir leben" nicht von gleichem Gebrauch schlechthin gesprochen werden. Daher sei eine letzte Lesart unseres Wörterbucheintrages 'Veterinär' Tierarzt vorgeschlagen:

Die Wörter Veterinär und Tierarzt folgen, wenn sie in usuellen Kotexten gebraucht werden, ähnlichen Gebrauchs- aber gleichen Bezugsregeln.

Wir können daher folgenden - auf die einsprachige Lexikographie zugeschnittenen - Synonymiebegriff definieren:

Zwei Wörter A und B einer Sprache L sind lexikalisch synonym genau dann, wenn hinsichtlich usueller Kotexte und relativ zum Referenzbereich "Realität, in der wir leben" die Gebrauchsregeln derart ähnlich sind, daß die Bezugsregeln gleich sind. ${ }^{101}$

In diesem Fall kann A für B und B für A als lexikalische Paraphrase stehen. Ein Wörterbuchbenutzer, der Sprecher von $L$ ist, kann dann aus $A$ den regelgerechten Gebrauch von B (und umgekehrt den von A aus B) für usuelle Kotexte und relativ zum Referenzbereich "Realität, in der wir leben" folgern.

\subsubsection{Bedeutungserklärungen aus einem Wort und Regelformulierungen}

Wenn wir die Bedeutung eines sprachlichen Ausdruckes als seine Gebrauchsregeln aufgefaßt haben, müssen wir aus diesem Ansatz folgende Konsequenz ziehen: Wenn die Bedeutung des Lemmas 'Veterinär' Gebrauchsregeln sein sollen und wenn Tierarzt eine Bedeutungserklärung oder lexikalische Para- 
phrase für 'Veterinär' sein soll, die funktioniert, dann muß Tierarzt e r s t e n s eine - zumindest verkürzte - Regelformulierung oder $z$ w e i t e n s ein gleichwertig funktionierender Ersatz für eine solche sein. ${ }^{102}$ Betrachten wir zunächst die erste Möglichkeit! Dann ergibt sich für Wörterbucheinträge der Form 'Lemma' Wort, ausgedrückt als Satzform: $y$ formuliert die Gebrauchsregeln für $x$, wobei die Ausdrücke, die für $\mathrm{x}$ eingesetzt werden können, keiner speziellen "Regelformulierungssprache" angehören ${ }^{103}$, sondern der gleichen Sprache wie die Lemmata. Nun läßt sich ein Wort wie z.B. Tierarzt nur schwer als Verkürzung etwa folgender vollständiger Regelformulierung auffassen: Wenn du, Wörterbuchbenutzer, mit dem Wort Veterinär regelhaft referieren und prädizieren willst, dann mußt du es in usuellen Kotexten und relativ zum Referenzbereich "Realität,..." wie das Wort Tierarzt gebrauchen. Schon der eben als "vollständige Regelformulierung" bezeichnete Wenn-dannSatz formuliert oder beschreibt ja nicht direkt eine Regel ${ }^{104}$, sondern nur indirekt, indem er auf ein anderes Wort und dessen Gebrauch verweist.

Es scheint mir daher zweckmäßiger, für die zweite Möglichkeit zu playdieren und die lexikalische Paraphrase Tierarzt als funtionierenden Ersatz für eine Regelformulierung aufzufassen. Mit ihr wird der Wörterbuchbenutzer vom Lexikographen aufgefordert, von dem als bekannt vorausgesetzten referierenden und prädizierenden Gebrauch des Wortes Tierarzt auf den Gebrauch des Wortes Veterinär - nach unserer Darstellung in usuellen Kotexten und relativ zum Referenzbereich "Realität..." zu schließen.

So gesehen können also Wörterbucheinträge der Form 'Lemma' Wort nicht nur als Behauptungen über Bedeutungsrelationen, sondern auch als Aufforderungen zum regelgerechten Sprachgebrauch aufgefaßt werden.

\section{Analyse der lexikographischen Praxis II. Wörterbucheinträge der Form 'Lemma' Syntagma und 'Lemma' Satz}

Die bisher vertretenen Auffassungen lassen sich auch auf Wörterbucheinträge der Form 'Lemma' Syntagma und 'Lemma' Satz ausweiten. Dazu folgen nun einige Bemerkungen. ${ }^{105}$

3.1. Die Austauschbarkeit salva veritate in Testsätzen und die Identifikation der Referenzobjekte für die Lemmata

Wir gehen von folgendem Wörterbucheintrag aus:

BEISPIEL Nr. 14

'Tier' Lebewesen, das sich von organischen Stoffen näbrt und sich bewegen und auf Reize reagieren kann. 
Ich brauche wohl nicht explizit darauf einzugehen, daß in den allermeisten Fällen eine Austauschbarkeit zwischen einem Lemma und dem bedeutungserklärenden Syntagma oder Satz, derart, daß bedeutungsgleiche Kotexte entstehen, nicht möglich ist. ${ }^{106}$

Es ist jedoch eine Austauschbarkeit salva veritate, d.h. derart möglich, daß logisch äquivalente Sätze z.B. folgender Form entstehen:

(29) Jedes $z$ ist ein $x$

(30) Jedes $z$ ist ein $y$

Dabei sind: $z$ eine Variable für (Nicht näher spezifierte) sprachliche Ausdrücke, $x$ eine für Lemmata und $y$ eine für lexikalische Paraphrasen.

Angewandt auf unser Beispiel Nr. 14 ergibt sich zunächst :

(31) Jedes $z$ ist ein Tier

(32) Jedes $z$ ist ein Lebe wesen, das sich von organiscben Stoffen näbrt und sich bewegen und auf Reize reagieren kann

Dabei gilt nun, daß die Satzformen (29) und (31) stets Sätze liefern, die in der alltäglichen Kommunikation gebraucht werden können, während die Satzformen (30) und (32) Sätze liefern, die als oder in Texten in Funktion kaum - es sei den als lexikalische Paraphrase - auftreten. ${ }^{107}$ Sätze von der Form (32) nenne ich daher Testsätze. Diese sind für den Lexikographen, nicht für den Wörterbuchbenutzer von Bedeutung. Aus (31) und (32) entstehen z.B. folgende Sätze:

(33) Jede Maus ist ein Tier

(34) Jede Maus ist ein Lebewesen, das sicb von organischen Stoffen näbrt und sich bewegen und auf Reize reagieren kann

Für (33) und (34) gilt nun nicht nur, daß (33) genau dann wahr ist, wenn (34) wahr ist und umgekehrt, sondern darüber hinaus, daß sowohl (33) als auch (34) genau dasjenige Referenzobjekt bzw. diejenige Klasse oder Teilklasse von Referenzobjekten identifizieren, auf die jemand in usuellen Kotexten das Wort Tier referierend oder prädizierend anwenden kann, wenn er über den Ref erenzbereich "Realität..." spricht.

3.2. Lexikalische Paraphrasen der Form Syntagma oder Satz als verkürzte Regelformulierungen

$\mathrm{Zu}$ fragen ist nun, wie Wörterbucheinträge der Form 'Lemma' Syntagma oder 'Lemma' Satz verstanden werden können. Für das Beispiel Nr. 14 kann folgende Lesart vorgeschlagen werden: 
Wenn x ein Gegenstand aus dem Referenzbereich "Realität..." und ein Lebewesen ist, und wenn $x$ sich von organischen Stoffen nährt, und wenn $x$ sich bewegen kann, und wenn $x$ auf Reize reagieren kann, dann ist in usuellen Kotexten das Wort Tier auf diesen Gegenstand regelhaft referierend und prädizierend beziehbar. ${ }^{108}$

Man kann diese Leseart auch folgendermaßen formulieren:

Können Urteile der Form: $x$ ist ein Lebewesen, $x$ näbrt sicb von organiscben Stoffen, $x$ kann sicb bewegen und $x$ kann auf Reize reagieren untereinander von $\mathbf{x}$ widerspruchslos behauptet werden, dann kann das Wort Tier in usuellen Kotexten auf $\mathbf{x}$ regelhaft prädizierend und referierend anwendet werden.

Im gewissen Unterschied zu den Wörterbucheinträgen der Form 'Lemma' Wort können in den Wörterbucheinträgen der Form 'Lemma' Syntagma/ Satz die lexikalischen Paraphrasen als verkürzte Regelformulierung aufge faßt werden. Die vollständige Regelformulierung für das Beispiel Nr. 14 könnte etwa so lauten: Wenn du, Wörterbuchbenutzer, mit dem Wort Tier regelhaft referieren und prädizieren willst, dann mußt du, wenn du usuelle Kotexte bildest, darauf achten, daß das Referenzobjekt die folgenden Eigenschaften hat: Es muß ein Lebewesen sein... etc.

\section{Schlußbemerkung: Umrisse eines Synonymiebegriffes für die einsprachige Lexikographie}

Wir hatten gesehen, daß im Falle von Wörterbucheinträgen der Form 'Lemma' Wort die lexikalische Paraphrase aus gerade einem Wort zu ihrem Lemma in der Relation der lexikalischen Synonymie steht.

Wir fragen nun abschließend, ob auch im Falle von Wörterbucheinträgen der Form 'Lemma' Syntagma oder 'Lemma' Satz die lexikalischen Paraphrasen, also Syntagmen oder Sätze, zum jeweiligen Lemma in einer Relation stehen, die begründet als Synonymie bezeichnet werden kann. Auf unser Beispiel Nr. 14 bezogen lautet die Frage demnach: Steht das Syntagma Lebewesen, das sicb von organischen Stoffen näbrt und sicb bewegen und auf Reize reagieren kann als lexikalische Paraphrase zum Lemma 'Tier' in einer Relation, die wichtige Eigenschaften mit der bereits beschriebenen Synonymierelation gemeinsam hat, so daß sie ebenfalls als Synonymie bezeichnet werden kann?

Um dieser Frage nachzugehen, sehen wir uns zunächst diejenigen lexikalischen Paraphrasen anhand unseres Beispiels Nr. 14 etwas genauer an, die nicht aus gerade einem Wort bestehen. Häufig wird die Auffassung vertreten, eine lexikalische Paraphrase wie Lebewesen, ... sei das Definiens 
einer Nominaldefinition und das Definiendum sei die Bedeutung eines zugehörigen Lemmas wie 'Tier', wobei die ganze Definition 'Tier' Lebewesen,... als eine analytische, d.h. als eine aufgefaßt wird, in der die Bedeutung des Lemmas nicht festgesetzt, sondern intensional aufgrund des Wortgebrauchs definiert wird. ${ }^{109}$ Nach dieser Auffassung steht somit eine lexikalische Paraphrase zu einem Lemma und dessen Bedeutung in einer Definitionsrelation; im allgemeinen ist diese aber nichts weiter als eine spezielle Relation der Bedeutungsgleichheit. ${ }^{110}$

Aus dieser Auffassung ergeben sich m.E. jedoch eine ganze Reihe von Nachteilen, die hier nicht einzeln diskutiert werden können. Auch liegt dieser Auffassung ein weitgehend internsemantisch konzipierter - m.E. für die Lexikographie nicht hinreichender - Bedeutungsbegriff zugrunde, nämlich einer, der davon ausgeht, daß die Bedeutung von Ausdrücken natürlicher Sprachen ohne oder wenigstens weitgehend ohne bezug auf die (nichtsprachliche) Welt beschrieben werden könne. M. E. bringt es auch mehr Nach- als Vorteile, im Zusammenhang mit der Erklärung des Status von Wörterbucheinträgen auf die letztlich nie vollständig durchgeführte aristotelische Unterscheidung von Nominal- und Realdefinition zurückzugreifen.

Ein Wörterbucheintrag der Form 'Lemma' Syntagma/Satz kann dagegen eher - im Anschluß an die Behandlung des Beispiels Nr. 1 - jenseits dieser Unterscheidung als eine lexikographische Behauptung aufgefaßt werden, in der - indem nicht $s \mathrm{t}$ i k t zwischen Sprache und Welt g e t $r$ e n n t wird - stets etwas Bestimmtes über die "res" und damit zugleich über die "nomina" und damit auch etwas über ihre wechselseitigen Beziehungen behauptet ist.

Daher kommt es, daß jemand, wenn er z.B. den "Wahrig" mit der Frage benutzt: Was ist ein Kajak? etwas Charakteristisches über Kajaks erfährt, damit aber zugleich etwas über den regelgerechten Gebrauch des Lemmas 'Kajak'. Schlägt er unter der Frage nach: Wie gebraucht man Kajak? erfährt er etwas über den regelgerechten Gebrauch dieses Lemmas, damit aber zugleich etwas Charakteristisches über Kajaks. Die Explikation dessen, was ein Wörterbuchbenutzer über den Gebrauch eines Lemmas eigentlich in der lexikalischen Paraphrase erfährt und wie das geschieht, hängt vom sprachtheoretischen Rahmen ab, innerhalb dem argumentiert wird. ${ }^{111}$ In dem hier gewählten Rahmen und anhand des Beispiels Nr. 14 kann folgende Auffassung vorgeschlagen werden. Mit der lexikalischen Paraphrase Lebewesen, ... wird eine Klasse von Elementen $\mathrm{x}$ beschrieben, denen alle die Eigenschaft zukommt, ein Lebewesen zu sein, und zwar ein solches, das sich von organischen Stoffen nährt, das sich bewegen kann und das 
auf Reize reagieren kann. Mit dem Wörterbucheintrag 'Tier' Lebewesen,... wird behauptet, daß der Wörterbuchbenutzer (in usuellen Kotexten und relativ zum Referenzbereich "Realität...") auf diejenigen $\mathrm{x}$ mit Tier regelgerecht referierend und prädizierend bezug nehmen kann, die die in der lexikalischen Paraphrase genannten Eigenschaften haben. Durch die lexikalische Paraphrase Lebewesen, ... erfährt der Wörterbuchbenutzer gerade diejenigen Beschaffenheiten, die ihm eine Identifikation desjenigen Referenzobjektes (oder der Klasse von Referenzobjekten) ermöglicht, auf die das Lemma 'Tier' (referenzbereich- und kotextspezifisch) bezogen werden kann. ${ }^{112}$ Damit lernt er die Bezugsregeln - als einen Teil der Bedeutung des Lemmas - aus der lexikalischen Paraphrase, die wir daher auch als verkürzte Regelformulierung aufgefaßt haben.

Da nun aber - wenn auch nicht alle, so doch einige - und zwar die für die lexikographische Praxis wichtigen Eigenschaften der Relation der lexikalischen Synonymie mit derjenigen Relation übereinstimmen, in der eine lexikalische Paraphrase, die ein Syntagma oder Satz ist, zu einem Lemma steht, kann diese Relation lexikographische Synonymie genannt werden. ${ }^{113}$ In dem hier gewählten theoretischen Rahmen kann sie wie folgt definiert werden: Ein Lemma A und eine lexikalische Paraphrase P (wobei P ein Syntagma oder Satz und aus der gleichen Sprache wie A ist) sind lexikographisch synonym genau dann, wenn $P$ ein Referenzobjekt oder eine Klasse von Referenzobjekten derart beschreibt, daß aus P die Bezugsregeln für A für usuelle Kotexte und relativ zum Referenzbereich "Realität...," erschlossen werden können. ${ }^{114}$

\section{Anmerkungen}

1 Der vorliegende Beitrag wurde für den Druck derart überarbeitet, daß erstens verschiedene Andeutungen in der Vortragsfassung ausgearbeitet und zweitens Anmerkungen hinzugefügt wurden. Dabei habe ich Anregungen aus der Diskussion des Vortrages aufgegriffen. Die Grundlinie der Argumentation der Vortragsfassung wurde beibehalten.

2 Vgl. Stötzel 1970 und Henne 1973, $597 \mathrm{f}$.

3 Den Ausdruck erklären verwende ich hier und nachfolgend nicht als Terminus, insbesondere nicht in spezifischem Unterschied zu bescbreiben.

4 J.C. Adelung, Grammatisch-kritisches Wörterbuch der Hochdeutschen Mundart, mit beständiger Vergleichung der übrigen Mundarten, besonders aber der Oberdeutschen. Bd. 1-4, 2. Aufl. Leipzig 1793 - 1801 [Neudruck Hildesheim, New York 1970], 1. Tl. VI.

5 Vorwort zur 5. Aufl. von Hermann Paul, Deutsches Wörterbuch. Bearb. von W. Betz. 6. Aufl. Unveränd. Studienausg. nach der 5., völlig neu bearb. u. erw. Aufl. Tübingen 1966, VI. 
Vorwort zu G. Wahrig, Deutsches Wörterbuch. Hrsg. in Zusammenarbeit mit zahlreichen Wissenschaftlern und anderen Fachleuten. Mit einem "Lexikon der deutschen Sprachlehre". Einmalige Sonderausg. - ungekürzt. Gütersloh 1968, 14.

Apresjan/Mel'Euk/Žolkovskij 1969 ; Arcaini 1967; Bahr 1974; Doroszewski 1973; Hartmann 1972; Henne 1972; Hoffer 1967; Lamb 1969; Read 1973; Dubois/Dubois 1971; Rey 1965 und 1970; Wahrig 1968; vgl, auch die Obersichtsartikel von Weinreich 1973, Quemada 1972 und Read 1973.

Vgl. Henne 1972.

Um für diesen Beitrag die Terminologie zu klären, gebe ich anhand der nachfolgenden Beispiele (a) bis (e) aus dem "Wahrig" (vgl. Anm. 6) einige Erläuterungen.

\section{(a) 'Ve.te·ri'när' $\langle\mathrm{m}$. 1 > Tierarzt}

Einen solchen Text nenne ich Wörterbucheintrag der Form 'Lemma' Wort. Diese Sprechweise berücksichtigt die Silbentrennungszeichen und die grammatische Informationen in den spitzen Klammern nicht. Entsprechendes gilt auch für die folgenden Beispiele (b)-(e); damit soll allerdings nicht gesagt werden, daß die genannten und andere Zeichen dem Wörterbuchbenutzer nicht auch semantische Informationen geben. Eine brauchbare Analyse dieser Zeichen im Hinblick auf ihre semantischen Funktionen gibt es nicht; auch Wahrig hat sich für sein Wörterbuch nicht hinreichend geäußert. Ich berücksichtige also in der Terminologie nur die "Bedeutungserklärung", die immer kursiv gesetzt ist, in (a) also Tierarzt; Tierarzt nenne ich eine lexikalische Paraphrase aus gerade einem Wort zum Lemma 'Veterinär'.

(b) 'Farm' <f. 20> Landgut, bes. mit Tierzucht (Geflügel $\sim$, Pelztier $\sim_{\text {, }}$ ) [engl. "landwirtschaftlicher Betrieb, Bauerngut ]

Einen solchen Text nenne ich Wörterbucheintrag der Form 'Lemma' Syntagma. Wiederum werden also die Informationen in \langle\rangle$,($ ) und [ ] nicht berücksichtigt. Die lexikalische Paraphrase ist hier also das Syntagma Landgut, bes. mit Tierzucht.

(c) 'Fa'sel lie se' <f. 19>zerstreutes, zerfabrenes Mädcben; Scbwätzerin [zu faseln ${ }^{2}$ ]

Diesen Text nenne ich Wörterbuchein trag der Form 'Lemma' Syntagma; Wort. Bei dieser Sprechweise ist berücksichtigt, daß die "Bedeutungscrklärung" angezeigt durch das Semikolon - in zwei lexikalische Paraphrasen aufgeteilt ist, in die 1. zerstreutes, zerfabrenes Mädchen und in die 2. Scbwätzerin; d.h.: ich fasse die "Bedeutungserklärung" als ein geordnetes Paar von lexikalischen Paraphrasen auf, und zwar deshalb, weil die Reihenfolge der lexikalischen Paraphrasen bei der semantischen Erklärung eine Rolle spielen kann.

(d) 'Hotte' <f. 19; südwestdt. > Butte, Tragkorb, Kiepe

Einen solchen Text nenne ich Wörterbucheintrag der Form 'Lemma' Wort 1,2,3.

Die Schreibweise drückt aus, daß die "Bedeutungserklärung" ein Tripel ist, in dem jedes Element ein lexikalische Paraphrase aus gerade einem Wort ist. (e) 'Ma.ga/'zin' <n. 11>Vorratsraum, Vorratshaus, Lagerraum, Lagerbaus; Raum zum Aufbewabren der Bücher einer Bibliotbek; Patronenkammer bei Mebrlade-Handfeuerwaffen (Gewehr $\sim$ ); meist bebilderte) Unterbalt ungszeitschrift [ < ital, magazzino "Vorrats-, Lagerraum" <arab. mabazin, Plural von mabzan "Warenniederlage, Lagerhaus" ]

Einen solchen Text nenne ich Wörterbucheintrag der Form 'Lemma' Wort 1,2,3,4, 
Syntagma $1,2,3$; d.h.: es handelt sich bei der "Bedeutungserklärung" um eine geordnete Menge, und zwar ein 7-Tupel, dessen Elemente 1.-4. lexikalische Paraphrasen aus gerade einem Wort sind und dessen Elemente 7.-9. lexikalische Paraphrasen sind, die die Form eines Syntagmas haben.

Die hier exemplarisch erläuterte Terminologie läßt sich systematisch auf alle Arten von Wörterbucheintrïge eines einsprachigen alphabetischen Wörterbuch übertragen und nach belieben verfeinern.

Was ich hier lexikaliscbe Paraphrase genannt habe, hat in der Literatur verschiedene Namen, z.B. semantiscbe Explikation (vgl. Henne 1972, 114 f) als Teil einer semantischen Deskription, lexikograpbiscbe Definition (vgl. Anm. 35) oder Definiens einer lexikographischen Definition.

10 Zum Begriff lexikalisch semantiscbe Mikrostruktur vgl. Wiegand 1970, $309 \mathrm{ff}$. u. Henne 1972, 153 ff., beachte Anm. 3 auf 155. Lexikalisch-semantische Mikrostrukturen lassen sich in verschiedenen theoretischen Rahmen darstellen; vgl. z.B. Wiegand 1972 mit Wiegand 1974 a-c. Es ist m.E. derzeit keineswegs ausgemacht, welcher Rahmen der geeignetste ist; auch eine ausgearbeitete Gebrauchstheorie der Bedeutung wird kaum ohne eine Darstellung von "Regelmäßig-" und "Regelhaftigkeiten" im Wortschatz auskommen.

11 So der Titel von Stötzel 1970.

12 Diese vorsichtige Formulierung geht auf die Lektüre von Jäger 1975 zurück. Das Hjelmslev sich als Saussure-Nachfolger begreif $t$, geht aus seinen Ausführungen öf ters hervor. Vgl. z.B. ders. in Hjelmslev 1974, 44 ff.

13 Dies wird deutlich, wenn man z.B. Bahr 1974 mit Nagy 1973 vergleicht.

14 Darauf wies auch Weinrich in seinem Vortrag über die Wahrheit der Worterbücher hin. M.E. müssen sich daher die Lexikographen/Lexikologen mehr mit der Frage befassen, wie Wörterbuchbenutzer aus Texten Wortbedeutungen rekonstruieren.

15 Es ist daher m.E. erstaunlich, daß innerhalb der Lexikologie bisher keine Typologie von kommunikativen Handlungsituationen entworfen wurde, aus der hervorgeht, von wem unter welchen Bindungen mit genau welchen Zwecken einsprachige Wörterbücher benutzt werden. Als Voraussetzung für eine solche Typologie fehlt eine empirisch fundierte Soziologie des Wörterbuchbenutzers. Unabhängig davon aber kann überlegt werden, in welchen Situationen überhaupt Menschen auf Wortbedeutungen reflektieren und eventuell zum Wörterbuch als Hilfe greifen. Eine typische Situation ist z.B. die des partiellen, wortsemantisch bedingten Kommunikationskonfliktes in Lektüresituationen, in denen keine Rückfragemöglichkeiten bestehen.

16 Ich habe hier von der sogenannten Gebraucbstbeorie der spracblicben Bedeutung gesprochen, weil es die Gebrauchstheorie der sprachlichen Bedeutung nicht gibt. Was es gibt, ist etwa folgendes: Ein nicht vollständig publiziertes Werk Wittgensteins. Darin finden sich verstreut auch einige Bemerkungen über den Zusammenhang von Bedeutung und Gebrauch (zusammengestellt z. B. bei Schmidt 1969, 19 u. bei Coope et al. 1972, 36). Schließlich gibt es eine sehr kontroverse Wittgenstein-Rezeption, in der u.a. versucht wird, das Problem der Bedeutung im Sinne von Wittgenstein zu behandeln. Dabei müssen natürlich auch jene dunklen Textstellen über den Zusammenhang von Bedeutung und Gebrauch berücksichtigt werden, weswegen es sich eingebürgert hat, 
summarisch von der "Gebrauchstheorie" zu sprechen. Dieser Usus darf allerdings nicht darüber hinwegtäuschen, daß es genau genommen im Detail sehr verschiedene - Bedeutungskonzepte "im Anschluß an Wittgenstein" gibt. Welches und ob überhaupt eines dieser Konzepte für die Lexikologie brauchbar ist, muß $\mathrm{m}$. E. erst noch erprobt werden; insbesondere muß erprobt werden, ob man in der Lexikographie mit einem nicht-repräsentativen Zeichenbegriff arbeiten kann. Als einen Ansatz in dieser Richtung versteht sich dieser Beitrag. - Zur Gebrauchstheoric vgl. z.B. Black 1973, 230 ff; Heringer 1974 a, $18 \mathrm{ff}$ und die Beiträge in Heringer 1974, Kutschera 1971, $218 \mathrm{ff}$.; Lewandowski, Bd. I, 218 f. und nicht in explizitem Anschluß an Wittgenstein Leisi $1967 \mathrm{u}$. Leisi et al. 1973, $33 \mathrm{ff}$.

17 Dieses und die Beispiele Nr. 10, 11, 13 sind Verschriftlichungen von Tonbandaufnahmen, die mit sprachlichen Angaben über den Kontext versehen sind.

18 Schlägt man im "Wahrig” unter 'Kajak' nach, findet man folgenden Wörterbucheintrag der Form 'Lemma' Syntagma; Wort 1,2. 'Ka-jak' <m.6>leichtes, bis auf den Sitz des Fabrers völlig geschlossenes Paddelboot des Eskimos; <allg.> Sportpaddelboot, Grönländer [eskimot., "einsitziges, gedecktes Männerboot']

Auffallend ist, daß die 1. lexikalische Paraphrase mit der Sachbeschreibung von Matthias im Beispiel Nr. 1 einige konstituive Elemente gemeinsam hat: in beiden ist wenigstens tentativ die aus der aristotelisch-scholastischen Logik bekannte Struktur eines Definiens "genus proximum + differentia specifica" exkennbar. Die Frage ist nur, wie man diesen Sachverhalt interpretiert; darauf kann hier im Einzelnen nicht eingegangen werden. Fest steht allerdings : eine solche Interpretation ist determiniert von dem zugrundegelegten Sprachzeichenbegriff bzw. Bedeutungskonzept. Implizite Bemerkungen dazu bei Eley 1974, $67 \mathrm{f}$. - Hier wird davon ausgegangen, daß es sich in einer lexikalischen Paraphrase weder um eine Nominal - noch um eine Realdefinition handelt, noch um eine Explikation der Wortbedeutung; auch wird das, was hier lexikalische Paraphrase genannt wird, nicht als eine "tentative semantische Merkmalanalyse" (vgl. Henne 1972,115) interpretiert, womit keineswegs behauptet werden soll, daß dies kein gangbarer Weg sei. Vielmehr wird die lexikalische Paraphrase als eine Sachbesch reibung zum Zwecke der Erläuterung eines Wortgebrauches aufgefaßt. Natürlich kann man auch sagen, daß damit intensional ein sprachgebundener Begriff konstituiert wird, der erwas mit der Bedeutung des Lemmas zu tun haben muß. Nur hier fangen eben die Schwierigkeiten an, die in diesem Beitrag nicht einmal angedeutet werden können.

19 Dieser Vorgang hat etwas mit sprachlich vermittelter Bildung von sprachgebundenen Alltagsbegriffen zu tun. Das gleiche gilt für die Lektüre eines Wörterbucheintrages.

20 Den Begriff der induktiven Verallgemeinerung gebrauche ich hier wie bei Wiegand 1974, 117.

21 Zum Begriff des usuelien Textes bzw. Kotextes vgl. Abschnitt 2.3.2.8.

22 Im Allgemeinen wird man davon ausgehen können, daß sich diejenige Sachinformation, die sich in einer lexikalischen Paraphrase findet, auch in dem entsprechenden Artikel einer Enzyklopädie findet aber nicht umgekehrt. Zur Abgrenzung von semasiologisch orientierten Wörterbüchern und Enzyklopädien vgl. auch Kubczak 1975, 74 f. . Im Anschluß an die dort geführte Ar- 
gumentation könnte man - wenn ich richtig verstanden habe - im hier gegebenen Rahmen etwa folgendermaßen formulieren: Die Intension eines Lemmas erfährt der Wörterbuchbenutzer durch die lexikalische Paraphrase(n), indem dort diejenigen Eigenschaften der Extension (der "Sache") genannt werden, die er wenigstens kennen muß, um das Lemma (in bestimmten Kotexten?, relativ zu einer bestimmten Welt? ) regelgerecht verwenden zu können.

Zur Relation der lexikalischen Hyponymie vgl. Lyons 1971, $463 \mathrm{ff}$, Welte, Bd. II, $500 \mathrm{f}$. und Wiegand 1973a, 44 ff.; dort habe ich - im Anschluß an Lyons - die lexikalische Hyponymie so definiert: "Wenn ein Satz $S_{i}$ einen Satz $S_{k}$ impliziert und $S_{j}$ und $S_{k}$ sich nur durch die Ausdrücke $A_{j}$ und $A_{k}$ in der gleichen syntaktischen Position unterscheiden, dann steht $\mathbf{A}_{i}$ zu $\mathbf{A}_{k}$ in der Relation der lexikalischen Hyponymie (und $\mathbf{A}_{\mathbf{k}} \mathbf{z u} \mathbf{A}_{\mathbf{i}}$ in der Relation der lexikalischen Supernymie)". Dort bin ich z. B. davon ausgegangen, daß sich derjenige Teil der Wortbedeutung, der die Darstellungs- oder Symbolfunktion der Sprache betrifft, der begriffliche Inhalt, sich mittels Merkmalen beschreiben läßt. Dann kann man in Ergänzung zu Lyons sagen : "Führt man eine Merkmalbeschreibung durch, in der der Inhalt eines Ausdruckes $A_{i}$ den Inhalt eines A usdruckes $A_{k}$ strikt inkludiert, dann steht $\mathbf{A}_{\mathrm{j}} \mathbf{z u} \mathbf{A}_{\mathbf{k}}$ in der Relation der lexikalischen Hyponymie" (Wiegand, 1973a, 47). - Die Art der Rekonstruktion inhaltlicher Ähnlichkeitsbeziehungen zwischen Wörtern, die man aus der alltäglichen Kommunikation kennt, wenn man die Sprache beherrscht, ist weitgehend determiniert vom sprachtheoretischen Rahmen, in dem argumentiert wird. Dazu ein einfaches Beispiel. Geht man mit Wimmer 1973, 8-14 z.B. davon aus, ein sprachliches Zeichen sei bilateral, zwischen Ausdruck und Inhalt (= Bedeutung) bestehe Interdependenz und die Bedeutung sei als Regel des Gebrauchs des sprachlichen Zeichens zu beschreiben, dann kann die Relation der lexikalischen Hyponymie z.B. so definiert werden : Ein Ausdruck $A_{i}$ steht zu einem Ausdruck $A_{k}$ in der Relation der lexikalischen Hyponymie genau dann, wenn alle Gebraucnsregeln (und zwar alle die einer bestimmten Klasse), nach denen $A_{i}$ (in bestimmten Kotexten) verwendet wird auch Regeln sind, nach denen $A_{k}$ verwendet wird aber nicht umgekehrt. - Die Brauchbarkeit der verschiedenen Definitionen hängt davon ab, welche der im Definiens benutzten Begriffe sich für bestimmte $Z$ wecke angemessener klären lassen, z.B. solche Begriffe wie Merkmal, Implikation oder Regel.

Vgl. dazu den Wörterbucheintrag in Anm. 18.

25 Daß Ähnlichkeitsbeziehungen zwischen Wörtern "in der Sprache gegeben sind" heißt einfach, daß Menschen, die die Sprache gelernt haben, diese auch gelernt haben können. Wir verstehen daher dies nur so weit, wie wir verstehen, was es heißt, daß einer eine Sprache gelernt hat. - Im übrigen lassen sich diese "inhaltlichen Ähnlichkeitsbeziehungen" auch als Beziehungen zwischen Regeln in Regelbeschreibungen angeben. Für die Lexikographie muß dabei prinzipiell gelten - wenigstens wenn es sich um einsprachig-alphabetische Wörterbücher handelt - daß diese Regelformulierungen der gleichen Sprache angehören wie das Lemma, für das die Regel formuliert wird.

26 Solche sprachlichen Paraphrasierungen sind natülich ko- und kontextspezifisch; daher taucht bereits hier die Frage auf: Wenn die lexikalischen Paraphrasen Systematisierungen alltagssprachlicher Paraphrasen sind, sind sie dann auch ko- und kontextspezifisch? Und wenn sie dies wären, relativ zu welchen Ko- und Kontexten? (Zu den Begriffen Ko- und Kontext vgl. die Bemerkun- 
gen in Anm. 91). - Es scheint mir auf jeden Fall problematisch, lexikalische Paraphrasen - ohne weitergehende Uberlegungen - so ohne weiteres als "Definitionen", "Explikationen" etc. von Langue-Bedeutungen der Lemmata auf zufassen, und dabei die Textsortenfrage vollständig zu vernachlässigen. Bereits G. Stern 1932, 42 ff. hat darauf hingewiesen, daß ein Begriff benötigt wird, der einen bestimmten Verwendungsbereich rekonstruiert, relativ zu dem semantische Feststellungen getroffen werden. Stern führ $t$ - mit den damals zur Verfügung stehenden Mitteln - den Begriff des traditional range ein und unterscheidet zwischen referential und semantic range. Stern, 43 schreibt: "The existence of a tradional range for all words in a language makes the language a normative system for the meanings, and it is this fact that makes semasiology a branch of linguistics $\left[\ldots J^{\prime \prime}\right.$. Ein mit den modernernen begrifflichen Mitteln gefaßter Begriff, mit dem herausgearbeitet werden kann, relativ zu welchen Klassen von Texten die lexikalischen Paraphrasen die Bedeutung der Lemmata paraphrasieren, ist $\mathrm{m}$.E. für die Praxis des Wörterbuchmachens unabdingbar und für die Rekonstruktion dieser Praxis ebenfalls notwendig. Einige - noch keineswegs hinreichende - Ansätze dazu finden sich im Abschnitt 2.3.2.8.

Zur Analytizität vgl. Quine 1972; Lewis 1975; vor allem aber den in der Linguistik wenig bekannten Sammelbd, von Weingartner 1966. Zur (Nicht-) Obersetzbarkeit vgl. Dolan 1969. Zur Definitionsproblematik vgl. die Literatur in Anm. 35. Zur Frage, ob die Synonymie eine Aquivalenz- oder Toleranzrelation ist, vgl. vor allem Fischer 1973. Zur Austauschbarkeit vgl. Mates 1952 und Jost 1970; die beiden Arbeiten zeigen, wie unterschiedlich das Problem behandelt werden kann. Zur Ähnlichkeit vs. Gleichheit vgl. Söll 1966. Zur Identität vgl. Scheffler 1955 und Carnap 1956; zu den semantischen Funktionen im Sinne Bühlers vgl. Heger 1971, 66; Baldinger 1968 und Wiegand 1970, 334 ff.

28 Ich verwende in diesem Beitrag die Termini Synonymie und Synonymität bedeutungsgleich.

29 Die Unterscheidung von alltagstheoretischem und wissenschaftlich-theoretischem Begriff kann hier nicht im einzelnen ausgeführt werden. Dazu nur ein Beispiel: Wenn jemand sagt, daß bei einem Fußballspiel die 10 Feldspieler der einen Mannschaft das gleiche Trikot anhaben, dann hat es wenig Sinn, ihm zu erwidern, die Trikots seien eigentlich nicht gleich sondern nur ähnlich, weil sie z.B. verschiedene Größen hätten. Denn hier wurde in Übereinstimmung mit alltäglichen Gebrauch des Wortes gleich geredet und dieser Gebrauch konstituiert einen alltagstheoretischen Begriff, auf dem ein wissenschaftlicher Begriff von Gleichheit allerdings aufruht; natürlich kann nicht in der gleichen (!) Weise verständlich $\mathbf{Z}$ B. über das principium identitatis indiscernibilium geredet werden; Dieses ist nur auf der Basis eines wissenschaftlich-theoretischen Gleichheitsbegriffes sinnvoll.

Searle 1971, 20.

31 Die bei Wahrig verwendete Plantin für die Stichwörter gebe ich stets durch einfache Anführungszeichen wieder.

32 Wahrig, Deutsches Wörterbuch, 22.

33 Ebd., 25, 5.4.

34 Ebd., 239. 

Weinreich 1967; Knudsen/Sommerfelt 1958; Rey 1965; Rey-Debove 1966 und 1967;

36 Wahrig 1973, $155 \mathrm{f}$.

37 Der Begriff "Realität, in der wir leben", den ich hier und im folgenden verwende (auch abgekürzt als "Realität...") ist hier nicht ausdrücklich definiert. Er läßt sich nur bis zu einem gewissen Grade präzisieren. Eine Definition läßt sich z.B. beim Übergang zu einem formalen Modell geben. Daran bin ich aber hier nicht interessiert. Hier soll mit dem Begriff nur darauf hingewiesen werden, daß es erforderlich ist, bei den Fragen der semantischen Erklärung in einem einsprachigen Wörterbuch einen Bezug zur Welt der Wörterbuchbenutzer zu berücksichtigen.

38 Vgl. dazu Anm. 18. Im übrigen gibt es in der Spezialliteratur zur Definition so unterschiedliche A uffassungen, daß dies zumindest indirekt zeigt, daß an dieser Unterscheidung etwas nicht stimmen kann. Man vgl. etwa folgende Arbeiten: Hempel 1956 (hier werden z.B. drei Arten von Realdefinitionen unterschieden). Die Hempel'sche Unterscheidung wird referiert bei Stegmüller 1967, 336 f.; Eley 1974, 62 ff, ; Menne 1973, 269; Klaus/Buhr 1972, Bd. I, 216 ff. ; Robinson 1965, passim; Tamas 1964; ich halte es daher für zweckmäßig, für die Lexikographie eine Unterscheidung von Nominal- und Realdefinition zu unterlassen, weil diese Unterscheidung nicht dazu beiträgt, Probleme zu lösen, die bei der Analyse und Herstellung lexikalischer Paraphrasen auftreten.

39 Natürlich können diese Anführungszeichen durch beliebige andere Schriftzeichen ersetzt werden, ohne daß sich die nachfolgende Argumentation dadurch ändert.

40 Vgl. zu diesen Varianten Heringer 1974a, 83 ff., Keller 1975, 26 ff. ; Beeh $1973,159 \mathrm{ff}$.

41 Quine 1972, $171 \mathrm{f}$.

42 Ebd., 173.

43 Ebd., 173.

44 Mir geht es dabei hier keineswegs darum, einen eingeführten Begriff wie "lexikographishe Definition" abzuschaffen, denn es ist ja klar, daß Definitionen auch Behauptungen sind. Es geht mir vielmehr darum, die Probleme der lexikalischen Paraphrasen und deren Behandlung von den Fragen des wissenschaftlichen Definierens zu trennen und sie Fragen von Behauptungshandlungen und deren Behandlung anzuschließen. - Auch Wunderlich 1974, 205 faßt die Definitionen begrifflicher Ausdrücke in der natürlichen Sprache als Behauptungen über Relationen von Begriffen auf.

45 Diese - allerdings weitergehenden Unterscheidungen - im Anschluß an Keller 1975, $56 \mathrm{f}$.

46 Vgl, Abschnitt 2.3.2.5. Zur F rage der Wahrheit von Wörterbucherklärungen vgl. auch Robinson 1965, $39 \mathrm{ff}$. 
Die Ausschaltung intensionaler Kotexte schafft bereits ein Kriterium, daß im Grunde für natürliche Sprachen nicht angemessen ist, da hier eben z.B. im Deutschen die Verben glauben und meinen und Texte, in denen diese auftreten, existieren und nicht einfach ausgeschlossen werden können. Wenn sie hier dennoch ausgeschlossen werden, dann erstens, weil sie insofern bei meiner weiteren Argumentation keine Rolle spielen, als nicht die Auffassung vertreten wird, die Symonymierelation sei als Relation der Bedeutungsgleichheit aufzufassen. Die Problematik von Synonymie, Substituierbarkeit und intensionalen Kotexten wird diskutiert in verschiedenen Beiträgen bei Linsky 1952.

Substitutive Synonymiebegriffe sind solche, bei denen einer der verschiedenen Substitutionsbegriffe als Kriterium für eine Synonymiebehauptung fungiert.

Vgl. Alston 1964, 36 ff.; Alston 1963 u. 1968 passim. Vgl. dazu die Auseinandersetzung bei Blose 1965, $302 \mathrm{ff}$.

50 Eine andere ist die folgende von Keller 1975, 48, Anm.1: "Zwei Sätze sind miteinander synonym, wenn und nur wenn jede beliebige Paraphrase des einen Satzes eine Paraphrase jeder beliebigen Paraphrase des anderen Satzes ist". Nun ist bei Keller, ebd. der Begriff der Paraphrase, der hier im Definiens steht, wie folgt definiert: "Zwei Sätze sind Paraphrasen voneinander, wenn und nur wenn sie dieselben Folgerungen haben und Folgerungen derselben Sätze sind und darüber hinaus diesselben Präsuppositionen haben". Damit ist die Feststellung der Synonymie von Sätzen von der Feststellung der Folgebeziehungen von Sätzen abhängig. - Weitere Beispiele finden sich bei Blose 1965 in dem Abschnitt "Synonymy as Mutual Entailment" und in der dort genannten Literatur. Auf zahlreiche der dort behandelten Probleme kann allerdings im nachfolgenden Exkurs nicht eingegangen werden.

51 Lyons $1969,450$.

52 Damit meine ich, daß 2.B. innerhalb der gener ativen Semantik kaum darüber nachgedacht wird, daß Begriffe, die relativ zu logischen Sprachen nützlich sind, nicht in der gleichen Weise gebraucht werden können, wenn es um natirliche Sprachen geht.

53 Lyons $1971,455 \mathrm{f}$.

54 Lyons $1969,445$.

55 Auf einige der nicht explizit genannten Voraussetzungen hat bereits Schnelle 1973, 255 ff. hingewiesen. Vgl. auch Wiegand $1973 \mathrm{c}, 86$.

56 In der Linguistik ist es üblich geworden, davon zu sprechen, daß jemand einen Satz äußert; auch Autoren, die gerade dargelegt haben, daß Sätze durch Abstraktion gewonnene linguistische Einheiten sind, sprechen anschließend ohne jedes Problembewußtsein davon, daß Sätze geäußert werden. Das nun heißt natürlich, daß von Sprachwissenschaftern definierte abstraktive Einheiten geäußert und damit materialisiert werden; nimmt man also diese Sprechweise beim Wort, ist sie ein glänzender Ausdruck für die Ontologisierung und/oder Psychologisierung grammatischer Strukturen, die als Ergebnisse sprachwissenschaftlicher Untersuchungen aufgestellt wurden. Dies heißt naturlich noch keineswegs, daß jeder Autor, der einmal davon gesprochen hat, daß jemand einen Satz geäußert hat etc. ein Vertreter einer solchen Ontologisierung von grammatischen Strukturen sein muß. Ich spreche daher weiter davon, daß 
jemand Sätze äußert, allerdings in dem Sinne, daß jemand etwas äußert, das von jemand, der über einen Begriff von Satz verfügt, als Satz erkannt wird. Lyons 1971, 430.

58 Wenn es richtig ist, daß man mit dem englischen und deutschen Satz (13) das gleiche behaupten kann, dann ist das eine der Rechtfertigungen dafür, daß es nötig ist, den Begriff der Proposition überhaupt einzuführen.

61 Den Begriff der "Situation" werde ich nicht näher definieren, da es im Rahmen dieses Beitrags kaum erforderlich ist.

62 Die Voraussetzung (a) und (b) können eventuell als eine Voraussetzung behandelt werden.

63 Der erste Satz unter (c) meint etwa folgendes: Im Falle z.B. solcher Sätze wie (13) und (13a) werden nur diejenigen Eigenschaften betrachtet, die die entsprechenden sogenannten "Obersetzungen" z.B. in einer prädikatenlogischen Sprache K haben. Nehmen wir z.B. als K diejenige Sprache, die in Mates 1965 (als Sparche L) konstruiert ist, dann ergeben sich als "Obersetzung" für (13) "Ma" und für (13a) "ᄀ Ma". Das nun heißt kurz erläutert aber Folgendes, und zwar am Beispiel von (13): (13) Jobn ist verbeiratet gibt an, in welcher Beziehung die Gegenstände (= Bedeutungen im Sinne Freges = Extensionen im Sinne Carnaps) aus einem genau festgelegten Bereich $B$ (= universe of discourse) stehen, die über eine Interpretationsfunktion der Prädikatskonstanten " $M$ " und der Individuenkonstante " $a$ " zugeordnet sind, und zwar: die Person aus B, die in (13) mit Jobn bezeichnet wird, und " $a$ " zugeordnet ist, ist ein Element derjenigen Klasse, die durch das Prädikat (ist) verbeiratet konstituiert wird und die " $M$ " zugeordnet ist. Damit sind " $M$ ", " $a$ " und " $M a$ " - wir wollen hier annehmen im Rahmen einer vollständigen Interpretation I - semantisch bestimmt. - Damit nun aber die zugeordneten Bedeutungen exakt sprachlich angegeben werden können, muß diejenige Sprache, aus der (13) und (13a) stammen, für die Zwecke der Interpretation I standardisiert werden. Das heißt nun natürlich, daß bei der sogenannten "Obersetzung" nicht nur einige Aspekte nicht berücksichtigt werden, sondern daß - indem (13) und (13a) standardisiert werden - damit ein anderer, für natürliche Sprache wenige sinnvoller Analytizitätsbegriff eingeführt wird, denn (13) und (13a) werden nun - wie ihre "Obersetzungen" - so behandelt, als seien sie formal und relativ analytisch! Wenn nun jemand " $M$ " explizi t be ha u tet (aussagt) und wenn er zugleich "r Ma" exp I i $z$ i t b e h a u $\mathrm{p}$ e $t$ (aussagt), dann kann er das natürlich nicht "without contradiction"; denn wenn "Ma" bei I den Wahrheitswert W hat, dann hat " $\neg$ Ma" bei I - nach der Wahrheitswerttafel des Negator " $\neg$ " den Wahrheits-

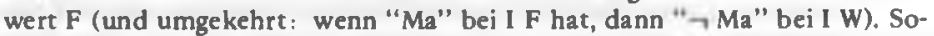
mit ist "MaA $\neg$ Ma" eine Kontradiktion. - Relativ zu K nun kann natürlich sowohl eine materiale Implikation als auch eine logische Implikation definiert werden, und bei irgendeiner festgesetzten Interpreataion I ist stets klar, welche Sätze welche anderen Sätze implizieren. Nur in diesem Fall ist nichts mehr davon abhängig, was Sprecher von $\mathrm{K}$ über Sätze aus $\mathrm{K}$ sagen ("Ist es vielleicht möglich, daß jemand z.B. "Ma" oder " $\neg \mathrm{Ma"} \mathrm{widerspruchslos} \mathrm{be-}$ hauptet?" kann nur eine sinnvolle Frage von jemand sein, der K nicht kennt.) 
Denn alles, was möglich ist, ist bereits von demjenigen festgesetzt und entschieden, der die Interpretation I zu K gemacht hat. Unter der Voraussetzung (c) wären als die ganzen pseudopragmatischen Bezugnahmen von Lyons überflüssig. -

Zu dem zweiten Satz unter (c) ist zu bemerken: Eine solche Obersetzungstheorie gibt es nicht. Bei der Obersetzung von Ausdrücken einer natürlichen Sprache in welche logische Sprache auch immer, gibt es stets zahlreiche Schritte, die mehr oder weniger willkürlich sind. Vgl. dazu z.B. Thiel 1965, $140 \mathrm{ff}$.; und grundsätzlich Kambartel 1968, 149 ff.; Mates 1965, 112 führt - nachdem er allerdings nur einige Schwierigkeiten erwähnt hat - aus: "Alle diese Schwierigkeiten lassen die Aufgabe, zur Symbolisierung von Aussagen der natürlichen Sprache präzise und praktisch verwendbare Regeln anzugeben, hoffnungslos erscheinen. Zumindest in den komplizierteren Fällen können wir nur den nichtsagend klingenden Rat geben: man frage sich nach dem Sinn der Aussage der natürlichen Sprache und versuche dann, eine Aussage von L [hier eine prädikatenlogische Sprache erster Stufe ohne Identität] zu finden, die relativ zu der vorliegenden Interpretation so weit wie möglich denselben Sinn hat."

$$
\text { Lyons 1971, } 455 \mathrm{f} \text {. }
$$

65 Schnelle 1973, 256 gibt "without contradiction" als "ohne Widerspruch" wieder, um dann verschiedene Arten von Widerspruch gegeneinander abzuwägen.

66 Ich bin nicht der Meinung, daß die Lyonsche Definition etwas mit der materialen Implikation zu tun hat. Anderer Auffassung ist Wunderlich 1974, 301.

67 Lyons $1971,455$.

68 Die wichtigste neuere Literatur zur Analytizität - soweit sie für Linguisten wichtig ist - findet sich bei Wiegand/Wolski 1975.

69 Lyons $1971,455$.

70 Vgl. Schnelle 1973, 257 und Wiegand 1974b, 686.

71 Die Obersetzung von entailment mit Einscblu $\beta$ nach Stammerjohann 1975. 103. Die hier gegebene Definition der analytischen Implikation (= entailment =Einschluß) ist übrigens insofern für linguistische Zwecke nicht sehr gut brauchbar, da die Praesuppositionsrelation von der Implikation nicht hinreichend getrennt werden kann. Das gelingt erst, wenn man die Definition durch einen Zusatz wie Keller 1975, 32 f., Anm. 2 erweitert.

72 Man kann natürlich an dieser Stelle eine ganze Reihe von Hilfskonstruktionen aufbauen, um diese Argumentation zu unterbinden: so könnte man z.B. sagen, daß der Streit über die Folgebeziehung dadurch entsteht, daß die Streitenden obwohl sie alle Deutsch sprechen - dennoch verschiedene Sprachen sprechen, wenn es um Ideologie geht. Damit kommt man zum Begriff der Ideologiesprache und damit zur Frage der Sprachen in einer Sprache. Vgl. dazu Pankoke 1966 und Rossipal 1973. Schließlich gelangt man dann zu der Frage bzw. dem Sachverhalt, daß Implikationsbezichungen kotextspezifisch sind und damit Bedeutungsrelationen auch. Das bedeutet z.B.: für manche Sprechergruppen der deutschen Sprachgesellschaft steht kommunistiscb zu totalitär in der lexikalischen Hyponymie, für andere dagegen nicht. Behauptungen sind daher - wenigstens für manche Wortschatzbereiche - nicht von vornherein als ideologiefrei zu betrachten. 
74 Zu den verschiedenen Analytizitätsbegriffen vgl. Frey 1970, $41 \mathrm{ff}$.

75 Ober "sichere" Kriterien verfügt der Beurteiler nur dann, wenn es z.B. darum geht, die lexikalischen Relationen innerhalb bestimmter Wortschatzbereiche zu beurteilen, etwa solche, auf die ich mich in Wiegand 1974a-c beschränkt habe. D.h. zugleich: Das Verfahren, lexikalische Bedeutungsrelationen zwischen Wörtern über die Implikationsbeziehungen von Sätzen zu konstituieren, funktioniert nur in bestimmten Kotexten; Oder anders ausgedrückt : bei der Beurteilung von Implikationsbeziehungen werden sich die Sprecher nur einigen können, wenn die in den Sätzen verwendeten deskriptiven Ausdrücke aus bestimmten Wortschatzbereichen stammen. In diesem Fall können sie sich allerdings meistens auch gleich darüber einigen, ob die infrage kommenden Wörter oder Sätze bedeutungsgleich sind oder nicht. Das soll natürlich nicht heißen, daß Implikationsbe ziehungen überhaupt nicht geeignet sind, Bedeutungsrelationen festzustellen. Solange die Ko- und Kontextfrage nicht geklärt ist, muß mit einer ganzen Reihe von provisos gearbeitet werden. Ein Begriff wie eingeschränkter Kontext im Sinne von Lyons (eine Art mißglückte Analogie zu logiksprachlichen Texten über einen bestimmten universe of discourse) hilft in dieser Frage nicht weiter.

77 Vgl. Camap 1956, 222 ff. Wunderlich 1974, 205 führt aus: "Beim Obergang zu einer konstruierten Sprache können die zwischen je zwei Ausdrücken bestehenden Sinnrelationen z.B. in Form von Bedeutungspostulaten wiedergegeben werden; dies bedeutet, daß hier keine Bedeutungs a $n$ a l y s e mehr geleistet werden soll, sondern daß eine bestimmte Bedeutungsrelation f $\mathrm{i} x$ i e r $t$ werden soll und damit als Beschränkung zu gelten hat für alle Interpretationen, bei denen einer der in Relation stehenden Ausdrücke eine Rolle spielt." Diesen Ausführungen kann man prinzipiell zustimmen, zugleich sind sie aber gut ge eignet $z u$ verdeutlichen, was der Unterschied einer lexikographischen Kodifikation, einem Wörterbuch im "traditionellen" Sinne und einem Lexikon innerhalb irgendeiner "formalen" Grammatik ist. Auch in einem Wörterbuch werden in den Wörterbucheinträgen Bedeutungsrelationen (= Sinnrelationen) formuliert und damit gibt es Beschränkungen zwischen den Ausdrücken in verschiedenen Wörterbucheinträgen. Aber diese Beschränkungen haben nicht stets zu gelten. Würde man z.B. die verschiedenen Sinnrelationen zwischen je zwei Ausdrücken, die in einem Wörterbuch behauptet sind, in einem Lexikon als Bedeutungspostulate formulieren, dann ist das eben mehr als eine bloße Obersetzung in eine konstruierte Sprache. Der Geltungsanspruch ändert sich; d.h. auch: Ein Wörterbuchbenutzer hat Erwartungen an ein Wörterbuch und ein Lexikon hat Erwartungen an den Lexikonbenutzer! Man könnte sich allerhand politische lehrreiche Anekdoten zu dieser - freilich (bewußt) überspitzten - Formulierung einfallen lassen.

79 Zu diesem Beispiel und weiteren damit zusammenhängenden Fragen vgl. Thiel 1965,138 ff. Zur intensionalen Isomorphie vgl. Carnap 1956.

Vgl. dazu Anm. 77. 
81 Der Begriff "Gebrauch" ist m.E. bisher nicht sehr klar herausgearbeitet worden. Vgl. dazu die verschiedenen Beiträge in Heringer 1974. Vgl. auch Lewandowski 1973, Bd. I, $218 \mathrm{f}$.

82 Zu den entsprechenden Textstellen bei Wittgenstein vgl. Anm. 16.

83 Zur nachfolgenden Behandlung des Beispiels wurde ich durch Keller 1975, $26 \mathrm{ff}$. angeregt.

84 Auf die Diskussion dieses Begriffes kann hier nicht eingegangen werden. Vgl. dazu Dummett 1959. Interessante Bemerkungen dazu neuerdings bei Habermas 1975.

85 Zum Begriff der Extension vgl. z.B. Kubczak 1975; Immler 1973.

86 Vgl. dazu z.B. Mates 1965.

87 Essler 1972, 36 f. führt aus: "Nicht alle Ausdrücke der Alltagssprache werden stets (oder fast stets) in ein und derselben Weise gedeutet, nicht alle werden konstant interpretiert (oder vergleichsweise konstant interpretiert); [...] Die Alltagssprache enthält daher Ausdrücke, die nicht von vornherein für einen bestimmten Gegenstand, für eine bestimmte Eigenschaft usw. stehen, deren Interpretation je nach Kontext und Situation beliebig festgelegt werden kann, die variabel interpretiert werden. Beispiele für derartige variabel interpretierte Ausdrücke sind "das Ding", "der Gegenstand", "das Objekt" usw., wie sie in "Das Ding ist rot" und "Der Gegenstand ist schwerer als jener Tisch" verwendet werden. [...] Dieser Vorzug der Alltagssprachen wird in die Modellsprachen übernommen. Die deskriptiven Ausdrücke werden deshalb in Konstanten und Variablen unterschieden, je nachdem, ob sie für konstante Interpretationen oder für variable (für wechselnde) Interpretationen vorgesehen sind. Die Festlegung des Vokabulars ist hierbei von der Art, daß stets eindeutig entschieden werden kann, ob ein deskriptiver Ausdruck eine Konstante oder eine Variable ist, im Gegensatz zu den Worterverzeichnissen der Alltagssprachen, bei denen das nicht immer ohne Willkürakte möglich ist." -

Wora uf Essler hier aber nicht eingeht, sind eben die interessanteren Vorzüge der Alltagssprache. Sehen wir einmal davon ab, was die Redeweise " [...] ohne Willkürakte [...] " besagen soll: es scheint mir klar zu sein, daß es ein besonderer Vorzug der Alltagssprache ist, daß gerade nicht stets entschieden werden kann, ob es sich um eine Konstante oder eine Variable handelt. Die meisten Wörter der natürlichen Sprache sins lexikalisch polysem oder anders ausgedrijckt: sie unterliegen auch in usuellen Kotexten unterschiedlichen Bezugsregeln. Im Wörterbuch erscheinen sie daher als variable Konstante. Ein gutes Beispiel ist der Wörterbucheintrag für Magazin (vgl. Anm. 9). Auch in Texten sind häufig viele deskriptiven Ausdrücke nicht wie Konstanten behandelt, sogar dann nicht, wenn man nur die Darstellungsfunktion und usuelle Texte berücksichtigt.

88 Eine systematische Analyse solcher Gebrauchshinweise in einsprachigen Wörterbïchern fehit noch. Bemerkungen dazu bei Rossipal 1973.

89 Vgl. dazu Keller 1975. In Wiegand 1973c, 84 habe ich "Referenzregel" wie hier "Bezugsregel" verwendet. Angesichts eines guten Dutzend verschiedener Referenzbegriffe ist das wenig zweckmäßig. 
91 Mit den Ausdrücken Text, Kotext, Kontext bin ich bisher liberal umgegangen. Nur einige Bemerkungen zum Gebrauch in diesem Beitrag. Ein Kotext ist eine Klasse von sprachlichen Texten. Für ein Element aus dieser Klasse, also einen bestimmten Text, sage ich hier im Allgemeinen ebenfalls Kotext, um damit anzudeuten, daß es mir in der Argumentation um die Klasse geht. Natürlich ist klar, daß niemand eine Klasse von Texten äußert, wenn er eine Äußerung macht. Die Unterscheidung Ko- vs. Kontext bezieht sich - wie in der neueren Literatur geläufig - auf den Unterschied sprachlich vs. nichtsprachlich.

92 Die Übersetzung von implicate nach Keller 1975, 24.

93 Noch schwieriger scheint mir eine Beurteilung zu sein, wenn die Antwort gelautet hätte: "Ein Hospital ist eben ein Krankenhaus". Das muß m.E. damit zusammen hängen, daß hier das durchsichtige Wort Krankenbaus prädizierend gebraucht ist, und diese Durchsichtigkeit [Haus für Kranke] eher den Blick auf das Gemeinte freigibt. I ch habe den Eindruck, daß bei der Beurteilung der Bedeutungsgleichheit der drei infrage kommenden Sätze das Prädikat den Ausschlag gibt. Zum Begriff der Durchsichtigkeit vgl. Gauger 1971.

94 Wie sich solche Beobachtungen generalisieren und erklären lassen, übersehe ich allerdings noch nicht genau.

95 Die Unterscheidung usuelle vs. nicht-usuelle Kotexte kann m.E.auch für die Behandlung von Redewendungen in einsprachigen Wörterbüchern von Nutzen sein. So steht bei Wahrig unter dem Lemma 'Tier' ..... u.a. sie ist ein 'gutes Tier' < fig.; umg.> sie ist gutmüt ig und ein bißcben dumm. Vergleicht man diese lexikalische Paraphrase mit der für 'Tier' (vgl. das Beispiel Nr. 14), dann sieht man leicht, daß die gegebene Unterscheidung bei der Analyse hilfreich sein kann.

96 Beispiel nach Wiegand $1973 \mathrm{c}, 84$.

97 Unter synthetischen Urteilen a posteriori verstehe ich hier solche, die Erfahrung aufgrund von Erfahrung erweitern.

98 Neben dem sprachtheoretischen Ansatz ist es daher das Kriterium der Austauschbarkeit, (das freilich nicht unabhängig von diesem Ansatz ist, aber auch nicht vollständig determiniert), das bzw. dessen unterschiedliche Fassung die Ursache dafür ist, daß die Anzahl der Synonymiedefinitionen so umgangsreich ist.

99 Ausdruck der semantischen Geschlossenheit (im Sinne Tarskis; daß manche die Lexik einer Einzelsprache als sog. of fenes System im Unterschied zu einem geschlossenen System der Phonologie auffassen, steht dazu nicht im Widerspruch) innerhalb der einsprachigen Wörterbücher ist der sog. lexikographische Zirkel; a us diesem kommt man auch nicht heraus, wenn man die Bedeutungserklärungen der Lemmata in den Status der Metasprache erhebt. Im Gegenteil: eine der interessanten Besonderheiten der lexikographischen Praxis besteht gerade darin, daß die "Bedeutungserklärung", unter Ausnutzung der Eigenschaft der Selbstreflexivität, im einsprachigen alphabetischen Worterbuch in der g l e i c hen S p r a ch e erfolgt; anderenfalls könnten lexikalische Paraphrasen ihre Aufgabe nicht erfüllen. 
$100 \mathrm{Vgl}$. dazu folgende Literatur: Schmaltz 1904; Hobstetter 1911; Reichelt 1965; Kuntze 1967; Widdra 1967.

101 Auch Müller 1965, 92 begreift Wórtsynonymie als Bedeutungsähnlichkeit und ko(n)textrelativen Begriff; er definiert: "Unter einem Synonym verstehen wir ein Wort, das in einem bestimmten kontextualen Zusammenhang trotz gewisser inhaltlicher und stilistischer Nuancen für ein anderes stehen, d.h. mit ihm ausgetauscht werden kann. Diese Austauschbarkeit besteht je doch nicht im Hinblick auf völlige inhaltliche Identität, sondern nur im Hinblick auf den festen Bezugspunkt im Text.". - Auch Gauger 1961, 173 faßt Synonymie als Bedeutungsähnlichkeit. - In Wiegand 1970, 340 habe ich ausgehend von und in Auseinandersetzung mit Heger - folgende Synonymiedefinition gegeben: "Synonymie liegt vor, wenn (1) onomasiologisch nachgewiesen werden kann, daß zwei oder mehrere lexikaliscbe Signeme ein- und desselben Sprachsystems ein- und dasselbe Noem enthalten und wenn (2) komplementär semasiologisch nachgewiesen werden kann, daß diesselben lexikalischen Signeme untereinander darstellungsf unktional in freier Distribution und somit symptom- und/oder signalf unktional in Opposition stehen." Diese Definition steht zu der hier gegebenen keineswegs im Widerspruch; sie ist lediglich in einem anderen theoretischen Rahmen gegeben und legt mehr Wert auf Systematisierungsmöglichkeiten intuitiver Urteile über die Synonymie. Der Begriff ist allerdings nicht kotextrelativ. Dafür ist er sprachsystemspezifisch, d.h. in beiden Definitionen wird von der Notwendigkeit ausgegangen, Synonymie relativ zu ... zu definieren. Synonymie wird in beiden Definitionen als Bedeutungsähnlichkeit aufgefaßt. - Im übrigen kann man wohl Welte 1974, Bd. II, 510 in folgender Ansicht zustimmen: "Die Existenz einer [...] Synonymie im Sinne einer 'Bedeutungsgleichheit' ist (für das System einer natülichen Sprache) weithin umstritten und wird heute im allgemeinen als widerlegt betrachtet'.

102 Auf die zweite Möglichkeit hat mich Keller mündlich aufmerksam gemacht. Vgl. auch Keller 1975, 29.

103 Eine spezielle Regelformulierungssprache kann man z.B. in einem fachsprachlichen Wörterbuch einführen.

104 Regel bescbreiben bzw. Regelbescbreibung und Regel formulieren bzw. Regelformulierung verwende ich in diesem Beitrag bedeutungsgleich; (das ist kein Widerspruch zu dem Welte-Zitat in Anm. 101, da es sich hier ja nicht um natürliche, sondern um Fachsprache handelt).

105 Ich rede hier von "Bemerkungen", da das folgende aus Platzgründen weniger ausgearbeitet ist als der Teil $I$.

$106 \mathrm{Vgl}$. 2.B. Lyons $1971,461 \mathrm{f}$. Es handelt sich also im folgenden nicht mehr um substitutive Synonymie.

107 In dem Moment, in dem ein Wörterbuchbenutzer lexikalische Paraphrasen liest, um die Bedeutung eines Lemmas zu erfahren, ist ein Wörterbucheintrag auch ein Text in Funktion.

108 In einem anderen sprachtheoretischen Rahmen würde man sagen: Tier hat das Merkmal (eventuell das Noem, das Sem) $>$ Lebewesen $<$. Man muß daher darüber reden, welche der beiden folgenden Redeweisen (hinsichtlich bestimmter Zwecke) weniger unangenehme Konsequenzen hat. (1) Ein bestimmter Ge- 
genstand, genannt Tier, hat die Eigenschaft, ein Lebewesen zu sein.

(2) Die Bedeutung eines bestimmten Wortes Tier, hat das Merkmal > Lebewesen < . Das Diskutieren bzw. Entscheiden geht natülich nicht ganz so einfach, wie das bei Keller 1975, 28 aussieht; denn natürlich haben nicht alle Autoren, die von Merkmalen sprechen, diese mit Eigenschaften von Dingen verwechselt und viele haben auch das Wort Junggeselle nicht mit Junggesellen verwechselt. Im übrigen scheint mir der Begriff der Eigenschaft kaum besser erklärt zu sein als der des Merkmals. (1) und (2) sind natürlich nicht die einzigen Möglichkeiten. Natürlich gibt es verschiedene, die zwischen (1) und (2) vermitteln. Wenn ich richtig sehe, war diese Position bei Brekle allerdings in der Tat nicht sehr klar gesagt - gemeint. Vgl. Brekle 1972, 31 und 95.

109 Vgl. die Literatur in Anm. 35.

110 Meistens wird dann zwischen der Definitionstelation und der Synonymierelation - verstanden als Bedeutungsgleichheit - nicht unterschieden. Vgl. 2.B. Eley 1974, 63: "Durch die [Nominal-] Definition wird bestimmt, daß das Definiens mit dem Definiendum bedeutungsgleich, d.i. synonym, ist." Vgl. dagegen das Quine-Zitat (Anm. 41).

111 Diese Explikation gehört m.E. zu den zentralen Punkten lexikologischer Forschung. Soweit ich sehe, wurde er bisher vernachlässigt.

112 Die "Auffindung" des Charakteristischen bzw. der hier angesprochenen Beschaffenheiten kann systematisiert werden; 2.B. kann man das aristotelischscholastische Definitionsverfahren - zusammengefaßt in dem Satz; definitio realis fit per genus proximum et differentiam specificam - in geeigneter Weise uminterpretieren. Dabei kommt es vor allem darauf an, daß man eine Kotextspezifik vorsicht.

113 Lexikographische Synonymie ist also deutlich von lexikalischer Synonymic zu unterscheiden. Sie haben eine Reihe gleicher und eine Reihe verschiedener Eigenschaften.

114 Abschließend sei noch auf eine interessante Stelle verwiesen, die in einem gänzlich anderen theoretischen Rahmen steht, aber in diesem offensichtlich etwas Ahnliches aussagen will. Ogden/Richards 1974, $241 \mathrm{ff}$. schreiben : "Die Frage der Synonyme führt uns von allein zur Betrachtung des 'richtigen Sprachgebrauchs' [...] . Ein Symbol ist zutreffend, wenn es einen Bezug hervorruft, der mit jenem übereinstimmt, den es bei jedem geeigneten Interpreten symbolisiert. Damit ergibt sich für jede gegebene Gruppe von SymbolBenuitzern eine gewisse Festlegung von etwas, das man richtige Bedeutung oder 'richtigen Sprachgebrauch' nennt. Es besteht die Tendenz, daß man von diesem Etwas als von d e r Bedeutung der in Frage stehenden Wörter spricht.' und etwas später heißt es: “Die Festlegung der Bezüge werden größtenteils durch den Gebrauch von Wbrterbüchern gestutzt und aufrechterhalten, und in vielen Zusammenhängen wären 'Bedeutung nach dem Wörterbuch' und 'richtiger Sprachgebrauch' Äquivalente. Das Wörterbuch ist eine Liste von Ersatz-Symbolen. Es sagt im Effekt: 'Dies kann unter den und den Umständen an die Stelle von jenem treten.' Das kann es deshab, weil unter diesen Umständen und für geeignete Interpreten die durch die beiden Symbole hervorgerufenen Bezüge hinreichend ähnlich sind. Das Wörterbuch dient also mehr dazu, die Oberlappungen zwischen den Bezuigen von Symbolen zu markieren als deren Bereiche zu definieren." 


\section{Literatur}

Den Herren Henne, von Held, Keller danke ich für zahlreiche mündliche Hinweise.

Alston, W.P., 1963: Meaning and use. In : Philosophical Quarterly 13. 107 - 124.

Alston, W.P., 1964: Philosophy of language. Englewood Cliffs/N.J.

Apresjan, Ju. D./I.A. Mel'čuk/ A.K. Žolkovskij 1969: Semantic and lexicography: Towards a new type of unilingual dictionary. In: F. Kiefer [Hrsg.] : Studies in syntax and semantics. Dordrecht. (=Foundation of Language, Supplement Series 10)

Arcaini, E., 1967: Semantica e lessico. In: Lingua e Stile 2. 291 - 333.

Bahr, J., 1974: Aspekte eines Lexikonmodells. Zur theoretischen Grundlegung der Lexikographie. In: Zeitschrift für germanistische linguistik 2. 145-170.

Baldinger, K., 1968: La synonymie - problèmes sẻmantiques et stylistiques. In: W. Th. Elwert [Hrsg.] : Probleme der Semantik (=ZFSL, Beih. NF 1). 41 - 61.

Beeh, V., 1973: Ansätze zu einer wahrheitswertfunktionalen Semantik. München. (=Linguistische Reihe 11)

Black, M., 1973: Sprache. Eine Einführung in die Linguistik. Obersetzt und kommentiert von H.E. Brekle. München. (=Kritische Information 1)

Blose, B.L., 1965: Synonymy. In: Philosophical Quarterly 15. 302 - 316.

Brekle, H.E., 1972: Semantik. Eine Einführung in die sprachwissenschaftliche Bedeutungslehre. München. (=UTB 102)

Camap, R., 1956: Meaning and necessity. A study in semantics and modal logic. 2. ed. Chicago/London.

Coope, Ch./ P. Geach/T. Potts/ R. White,1972: Wittgenstein-Obungsbuch. Aus dem Englischen von W. Grafe. Frankfurt 1972. (=Ludwig Wittgenstein. Schriften. Beiheft 2)

Dolan, J.M., 1969: Translation and meaning: an examination of Quine's translational indeterminacy hypothesis. Dissertation. Stanford Univercity.

Doroszewski, W., 1973: Elements of lexicology and semiotics. Translation by I. Taylor. The Hague. Paris. (=Approaches to semiotics 46)

Dubois, J./ Cl. Dubois, 1971 : Introduction a la lexicographie. Paris

Dummett, M.A.E., 1959: Wittgensteins philosophy of mathematics. In: The Philosophical Review 68. 324 - 348.

Eley, L., 1974: Definition, Begriffsbildung. In: H. Rombach [Hrsg.] : Wissenschaftstheorie. Bd. II : Struktur und Methode der Wissenschaften. Freiburg. Basel. Wien. (Studienführer zur Einführung in das kritische Studium der Erziehungsund Sozialwissenschaften)

Essler, W.K., 1972: Analytische Philosophie I. Methodenlehre. Sprachphilosophie. Ontologie. Erkenntnistheorie. Stuttgart. (=Kröners Taschenausgabe 440) 
Fischer, W.L., 1973: Ãquivalenz- und Toleranzstrukturen in der Linguistik. Zur Theorie der Synonyma. München. (=Linguistische Reihe 15)

Frey, G., 1970: Philosophie und Wissenschaft. Eine Methodenlehre. Stuttgart [usw.] (=Urban-Taschenbücher 133)

Gauger, H.-M., 1961: Ober die Anfänge der französischen Synonymik und das Problem der Synonymie. Dissertation Tübingen.

Gauger, H.-M., 1971 : Durchsichtige Wörter. Zur Theorie der Wortbildung. Heidelberg (Bibliothek der Allgemeinen Sprachwissenschaft)

Grice, H.P., 1957: Meaning. In: Philosophical Review 66. 377 - 388.

Grice, H.P., 1968: Utterer's meaning, sentence-meaning, and word-meaning. In: Foundations of Language 4. 255 - 242.

Grice, H.P., 1969: Utterer's meaning and intentions. In: Philosophical Review 78. $147-177$.

Habermas, J., 1975 : Sprachspiel, Intention und Bedeutung. Zu Motiven von Sellars und Wittgenstein. In: R. Wiggershaus [Hrsg.] : Sprachanalyse und Soziologie. Die sozialwissenschaftliche Relevanz von Wittgensteins Spätphilosophie. Frankfurt (=suhrkamp taschenbuch wissenschaft 123). 319 - 340.

Hartmann, R.R.K., 1972: Ober den Einfluß der linguistsichen Semantik auf die englisch-amerikanische Lexikographie. In : Linguistik und Didaktik 11. 197-208.

Heger, K., 1971 : Monem, Wort und Satz. Tübingen. (=Konzepte der Sprach- und Literaturwissenschaft 8)

Hempel, C.G., 1956: Fundamentals of concept formation in empirical science. In : International Encyclopedia of Unified Science. Bd. II, 7., 3. A uflage 1956.

Henne, H., 1972: Semantik und Lexikographie. Untersuchungen zur lexikalischen Kodifikation der deutschen Sprache. Berlin. New York. (=Studia Linguistica Germanica 7)

Henne, H., 1973: Lexikographie. In: H.P. Althaus/ H. Henne/ H.E. Wiegand [Hrsg.] : Lexikon der Germanistischen Linguistik. Tübingen. 590 - 601.

Heringer, H.J., 1974: [Hrsg.] : Seminar: Der Regelbegriff in der praktischen Semantik. (=suhrkamp taschenbuch wissenschaft 94)

Heringer, H.J., 1974a: Praktische Semantik. Stuttgart.

Hjelmslev, L., 1974: Aufsätze zur Sprachwissenschaft. Hrsg. von E. Barth. Stuttgart.

Hobstetter, K., 1911: Zur Etymologie des Wortes Veterinär. In: Zeitschrift für Veterinärkunde 23. $237-238$.

Hoffer, B.L., 1967: Linguistic principles in lexicography. Diss. Univ. of Texas.

Immler, M., 1973: Versuch einer integrierten Theorie von Bedeutung, Referenz, Kompetenz und Performanz. In: Papiere zur Linguistik 5. 89-115.

Jäger, L., 1975: Zu einer historischen Rekonstruktion der authentischen SprachIdee F. de Saussures. Diss. Düsseldorf.

Jost, H., 1970: Zum Problem der wechselseitigen Austauschbarkeit synonymer lexikalischer Einheiten. In: Wissenschaftliche Zeitschrift der Universität Leipzig. Gesellschafts- und sprachwissenschaftliche Reihe 19. 509 - 516. 
Kambartel, F., 1968: Erfahrung und Struktur. Bausteine zu einer Kritik des Empirismus und Formalismus. Frankfurt. (=Theorie 2)

Keller, R.: 1975: Wahrheit und kollektives Wissen. Zum Begriff der Präsupposition. Düsseldorf.

Klaus, G./ M. Buhr, 1972: Philosophisches Wörterbuch. Bd. I und II. Berlin.

Knudsen, T./ A. Sommerfelt, 1958: Principles of unilingual dictionary definitions. In: Proceedings of the Eighth International Congress of Linguists. Oslo. $92-115$.

Kuntze, W., 1967: Herkunft und Bedeutung des Wortes Veterinär In: Deutsche tierärztliche Wochenschrift 74. 1967. $250-260$.

Kubczak, H., 1975: Das Verhältnis von Intension und Extension als sprachwissenschaftliches Problem. Tübingen. (=Forschungsberichte des Instituts für deutsche Sprache Mannheim 23)

Kutschera, F. von, 1971: Sprachphilosophie. München. (=UTB 80)

Lamb, S.M., 1969: Lexicology and semantics. In: A.A. Hill [Hrsg.] : Linguistics today. New York/London 1969, 40 - 49.

Leisi, E., 1967: Der Wortinhalt. Seine Struktur im Deutschen und Englischen. 3. durchgesehene und erweiterte Auflage, Heidelberg

Leisi, E., unter Mitwirkung von D. Weniger und W. Naef 1973: Praxis der englischen Semantik. Heidelberg (Sprachwissenschaftliche Studienbücher).

Leonard, H.S., 1967: Synonymy and systematic definitions. In: The Monist 51. $33-68$.

Lewandowski, Th., 1973: Linguistisches Wörterbuch. Bd. I. Heidelberg. (=Grundlagen der Sprachdidaktik. UTB 200)

Lewis, D., 1975: Konventionen. Eine sprachphilosophische Abhandlung. A us dem Amerikanischen übersetzt von R. Posner und D. Wenzel. Berlin. New York (de Gruyter Studienbuch. Grundlagen der Kommunikation).

Linsky, L., 1952: [Hrsg.] : Semantics and the philosophy of language. Urbana /III .

Lyons, J., 1969: Introduction to theoretical linguistics. Cambridge. [Reprint].

Lyons, J., 1971: Einführung in die moderne Linguistik. Aus dem Englischen übertragen von W. u. G. Abraham. Für den deutschen Leser eingerichtet von W. Abraham. München.

Marcus, S., 1970: Définitions logiques et definitions lexicographiques In: Langages 19. $87-91$.

Mates, B.: Synonymity. In: Linsky 1952. 111 - 136.

Mates, B., 1965 : Elementare Logik (Prädikatenlogik der ersten Stufe). Aus dem Amerikanischen übersetzt von A. Oberschelp. Göttingen. (=Moderne Mathematik in elementarer Darstellung 9)

Menne, A., 1973: Definition. In: H. Krings/ H.M. Baumgartner/ Ch. Wild [Hrsg.] : Handbuch philosophischer Grundbegriffe. Studienausgabe Bd. I: Das Absolute-Denken. München. 268 - 274. 
Müller, W., 1965: Probleme und Aufgaben deutscher Synonymik. In : Die wissenschaftliche Redaktion 1.90-101.

Nagy, G.O., 1973: Abriss einer funktionalen Semantik. The Hague. Paris. (=Janua linguarum. ser. minor 137)

Ogden, C.K./ I.A. Richards, 1974: Die Bedeutung der Bedeutung (The Meaning of Meaning). Eine Untersuchung über den Einfluß der Sprache auf das Denken und über die Wissenschaft des Symbolismus. Aus dem Englischen von G.H. Müller. Frankfurt (Theorie)

Pankoke, E., 1966: Sprache in "sekundären Systemen". Zur soziologischen Interpretation sprachkritischer Befunde. In: Soziale Welt 17. 253-273.

Pottier, B., 1965: La deffinition sémantique dans les dictionnaires. In: Travaux de Linguistique et de Littérature 3. 33 - 39.

Quemada, B., 1972: Lexicology and lexicography. In: Sebeok, T.A. [Hrsg.] : Current trends in linguistics. The Hague. Paris. Bd. 9. 395 - 475.

Quine, W.V.O., 1972; Zwei Dogmen des Empirismus. In: J. Sinnreich [Hrsg.] : Zur Philosophie der idealen Sprache. Texte von Quine, Tarski, Martin, Hempel und Camap. München. (=dtv. WR 4113)

Read, E.W., 1973: The segmenting of meanings in lexicogr aphical partice. In : Linguistics 105. $106-113$.

Reichelt, D., 1965: Herkunft der Berufsbezeichnung Veterinör und tierärztliche Berufsbezeichnungen im deutschen und europäischen Sprachgebrauch. Hannover [Dissertation Tierärztliche Hochschule].

Rey, A., 1965: A propos de la définition lexicographique. In : Cahiers de Lexicologie 6. $57-80$.

Rey, A., 1970: La Lexicologie: Lectures. Paris. (=Inition a la Linguistique. Ser. A.2)

Rey-Debove, J., 1966: La définition lexicographique: recherches sur l'equation semique. In: Cahiers de Lexicologie 6. 71 - 94.

Rey-Debove, J., 1967: La définition lexicographique: base d'une typologie formelle. In: Travaux de Linguistique et de Litterature 5. 141 - 159.

Rossipal, H., 1973: Konnotationsbereiche, Stiloppositionen und die sogenannten "Sprachen" in der Sprache. Hildesheim. (=Germanistische Linguistik 4. 1973)

Robinson, R., 1965: Definition. 4. Auflage, Oxford.

Scheffler, I., 1955: On synonymy and indirect discourse. In: Philosophy of Science 22. $39-44$.

Schnelle, H., 1973: Sprachphilosophie und Linguistik. Prinzipien der Sprachanalyse a priori und a posteriori. Reinbek bei Hamburg. (=rororo studium 30).

Schmaltz, R., 1904: Arendt und kein Ende [Etymologie des Wortes Tierarzt]. In: Berliner tierärztliche Wochenschrift. 242 - 243.

Schmidt, S.J., 1969: Bedeutung und Begriff. Zur Fundierung einer sprachphilosophischen Semantik. Braunschweig. (=Wissenschaftstheorie. Wissenschaft und Philosophie 3)

Searle, J.R., 1971 : Sprechakte. Ein sprachphilosoph ischer Essay. Aus dem Englischen von R.u.R. Wiggershaus. Frankfurt (Theorie). 
S6ll, L., 1966: Synonymie und Bedeutungsgleichheit. In: Germanisch-Romanische Monatsschrift. NF. $16.90-99$.

Stegmüller, W., 1967: Wissenschaftstheorie. In: A. Diemer/ I. Frenzel [Hrsg.]: Philosophie. Frankfurt. Hamburg (=Das Fischer Lexikon 11. Neuausgabe). $334-360$.

Stern, G., 1932: Meaning and change of meaning. With speccial reference to the English language. Göteborg. (Göteborgs Högskolas Ärsskrift 38)

Stetter, Ch., 1974: Sprachkritik und Transformationsgrammatik. Zur Bedeutung der Philosophie Wittgensteins für die sprachwissenschaftliche Theoriebildung. Düsseldorf.

Stötzel, G., 1970: Das Abbild des Wortschatzes. Zur lexikographischen Methode in Deutschland von 1617 - 1967. In: Poetica 3. 1 - 23.

Tamás, G., 1964: Die wissenschaftliche Definition. Budapest.

Wahrig, G., 1968: Neue Wege der Wörterbucharbeit. Gleichzeitig ein Beitrag einer strukturalistischen Bedeutungslehre. 2. Auflage. Hamburg (Berichte des Instituts für Buchmarktforschung. Sonderreihe).

Wahrig, G., 1973: Anleitung zur grammatisch-semantischen Beschreibung lexikalischer Einheiten. Versuch eines Modells. Tübingen. (=Linguistische Arbeiten 8)

Weingartner, P., 1966: [Hrsg.] : Deskription, Analytizität und Existenz. Salzburg. München (Drittes und Viertes Forschungsgespräch. Internationales Forschungszentrum für Grundlagen der Wissenschaften Salzburg).

Weinreich, U., 1963: Lexicology. In: T.A. Sebeok [Hrsg.] : Current trends in linguistics. The Hague. Paris. Bd. 1. 60 - 93.

Weinreich, U., 1967: Lexicographic definition in descriptive semantics. In: F.W. Householder/ S. Saporta [Hrsg.] : Problems in lexicology. Bloomington. $25-44$.

Widdra, K., 1967: Zu W. Kuntze, Herkunft und Bedeutung des Wortes Veterinär. In: Deutsche tierärztliche Wochenschrift 74. 465 - 467.

Wiegand, H.E., 1970: Synchronische Onomasiologie und Semasiologie. Kombinierte Methoden zur Strukturierung der Lexik. Hildesheim. (=Germanistische Linguistik 3. 1970)

Wiegand, H.E., 1973: Einige Grundbegriffe der lexikalischen Semantik. In: Funkkolleg Sprache. Eine Einführung in die moderne Linguistik. Bd. II (=Fischer Taschenbuch 6112). 23 - 39.

Wiegand, H.E., 1973a: Lexikalische Strukturen I. In: Funkkolleg [...]. 40 - 54.

Wiegand, H.E., 1973b: Lexikalische Strukturen II. In: Funkkolleg [...]. 55 - 69.

Wiegand, H.E., 1973c: Zeichenbegriff, Intern- und Referenzsemantik. Marginalien zu einigen Auffassungen D. Wunderlichs. In: Zeitschrift für germanistische linguistik 1.67- 99.

Wiegand, H.E., 1974: Einige Grundbegriffe der Modellbildung. In: Lehrgang Sprache. Einführung in die moderne Linguistik. Bearbeitete Neuausgabe der Studienbegleitbriefe zum Funkkolleg Sprache. Hrsg. vom Deutschen Institut für Fernstudien an der Universität Tübingen. Weinheim. Basel. Tübingen, 88- 142. 
Wiegand, H.E., 1974a: Einige Grundbegriffe der lexikalischen Semantik. In : Lehrgang Sprache [...]. 654 - 679.

Wiegand, H.E., 1974b: Lexikalische Strukturen 1. In: Lehrgang Sprache [...], 680 701.

Wiegand, H.E., 1974c: Lexikalische Strukturen II: In: Lehrgang Sprache [...], 702 728.

Wiegand, H.E./ W. Wolski 1975: Zum Stand einer "gesellschaf tsbezogenen Semasiologie. Marginalien anhand der "Einführung in die Semasiologie" von Thea Schippan. Mit einer Arbeitsbibliographie zur Semantik in der Logik, Sprachphilosophie, Linguistik und Psycholinguistik 1963 - 1973/74. Hildesheim. (=Germanistische Linguistik 1975)

Wimmer, R., 1973: Der Eigenname im Deutschen. Ein Beitrag zu seiner linguistischen Beschreibung. Tübingen. (=Linguistische Arbeiten 11)

Wunderlich, D., 1974: Grundlagen der Linguistik. Reinbek bei Hamburg. (=rororo studium 17) 